\title{
$\beta$-Secretase BACE1 Promotes Surface Expression and Function of Kv3.4 at Hippocampal Mossy Fiber Synapses
}

\author{
[DStephanie Hartmann, ${ }^{1,2}$ Fang Zheng, ${ }^{1}$ Michele C. Kyncl, ${ }^{1}$ SSandra Karch, ${ }^{1}{ }^{\circledR}$ Kerstin Voelkl, ${ }^{1}$ Benedikt Zott, ${ }^{3}$ \\ ๑Carla D’Avanzo, ${ }^{2}$ @Selene Lomoio, ${ }^{4}$ Giuseppina Tesco, ${ }^{4}{ }^{\circledR}$ Doo Y. Kim, ${ }^{2 *}$ Christian Alzheimer, ${ }^{1 *}$ and $\odot$ Tobias Huth ${ }^{1 *}$ \\ ${ }^{1}$ Institute of Physiology and Pathophysiology, Friedrich-Alexander-Universität Erlangen-Nürnberg, 91054 Erlangen, Germany, ${ }^{2}$ Genetics and Aging \\ Research Unit, Institute for Neurodegenerative Disease, Massachusetts General Hospital, Harvard Medical School, Charlestown, Massachusetts 02129, \\ ${ }^{3}$ Institute of Neuroscience, Technical University of Munich, 80802 Munich, Germany, and ${ }^{4}$ Alzheimer's Disease Research Laboratory, Department of \\ Neuroscience, Tufts University School of Medicine, Boston, Massachusetts 02111
}

The $\beta$-secretase $\beta$-site APP-cleaving enzyme 1 (BACE1) is deemed a major culprit in Alzheimer's disease, but accumulating evidence indicates that there is more to the enzyme than driving the amyloidogenic processing of the amyloid precursor protein. For example, BACE1 has emerged as an important regulator of neuronal activity through proteolytic and, most unexpectedly, also through nonproteolytic interactions with several ion channels. Here, we identify and characterize the voltage-gated $\mathrm{K}^{+}$channel 3.4 (Kv3.4) as a new and functionally relevant interaction partner of BACE1. Kv3.4 gives rise to A-type current with fast activating and inactivating kinetics and serves to repolarize the presynaptic action potential. We found that BACE1 and Kv3.4 are highly enriched and remarkably colocalized in hippocampal mossy fibers (MFs). In BACE1 ${ }^{-1-}$ mice of either sex, Kv3.4 surface expression was significantly reduced in the hippocampus and, in synaptic fractions thereof, $\mathrm{Kv} 3.4$ was specifically diminished, whereas protein levels of other presynaptic $\mathrm{K}^{+}$channels such as $\mathrm{K}_{\mathrm{Ca}} 1.1$ and $\mathrm{K}_{\mathrm{Ca}} 2.3$ remained unchanged. The apparent loss of presynaptic Kv3.4 affected the strength of excitatory transmission at the MF-CA3 synapse in hippocampal slices of BACE1 ${ }^{-1-}$ mice when probed with the Kv3 channel blocker BDS-I. The effect of BACE1 on Kv3.4 expression and function should be bidirectional, as predicted from a heterologous expression system, in which BACE1 cotransfection produced a concomitant upregulation of Kv3.4 surface level and current based on a physical interaction between the two proteins. Our data show that, by targeting Kv3.4 to presynaptic sites, BACE1 endows the terminal with a powerful means to regulate the strength of transmitter release.

Key words: Alzheimer's disease; BACE1; hippocampal mossy fibers; Kv3; synapse; trafficking

Significance Statement

The $\beta$-secretase $\beta$-site APP-cleaving enzyme 1 (BACE1) is infamous for its crucial role in the pathogenesis of Alzheimer's disease, but its physiological functions in the intact nervous system are only gradually being unveiled. Here, we extend previous work implicating BACE1 in the expression and function of voltage-gated $\mathrm{Na}^{+}$and $\mathrm{K}^{+}$channels. Specifically, we characterize voltagegated $\mathrm{K}^{+}$channel $3.4(\mathrm{Kv} 3.4)$, a presynaptic $\mathrm{K}^{+}$channel required for action potential repolarization, as a novel interaction partner of BACE1 at the mossy fiber (MF)-CA3 synapse of the hippocampus. BACE1 promotes surface expression of Kv3.4 at MF terminals, most likely by physically associating with the channel protein in a nonenzymatic fashion. We advance the BACE1-Kv3.4 interaction as a mechanism to strengthen the temporal control over transmitter release from MF terminals.

\section{Introduction}

The $\beta$-site APP-cleaving enzyme 1 (BACE1) has garnered an infamous reputation as the enzyme initiating the amyloidogenic

Received Sept. 13, 2017; revised Feb. 19, 2018; accepted Feb. 28, 2018.

Author contributions: S.H. and T.H. wrote the first draft of the paper; S.H., D.Y.K., C.A., and T.H. edited the paper; S.H., C.D., S.L., G.T., D.Y.K., C.A., and T.H. designed research; S.H., F.Z., M.C.K., S.K., K.V., and B.Z. performed research; S.H., F.Z., M.C.K., S.K., K.V., and T.H. analyzed data; C.A. wrote the paper.

This work was supported by the Deutsche Forschungsgemeinschaft (INST 90/675-1 FUGG to C.A.), StaedtlerStiftung (C.A.), the National Institutes of Health (Grant AG014713 to D.Y.K.), Dr. Ernst und Anita Bauer-Stiftung (S.H.), and the Studienstiftung des deutschen Volkes (S.H., S.K., and K.V.). We thank Dr. Ulf Neumann and Dr. Derya processing of the amyloid precursor protein (APP). Through the release of neurotoxic amyloid $\beta$-peptides, this pathway is widely considered an essential pathogenic mechanism in Alzheimer's disease (AD) (Vassar et al., 2014). Notwithstanding the pivotal

R. Shimshek, Novartis Institutes of BioMedical Research, Neuroscience, Basel, for kind support and providing BACE inhibitor NB-360-containing food pellets; Dr. Sabine Hessler for initial experimental support; the Optical Imaging Centre Erlangen for imaging support; and Iwona Izydorczyk, Annette Kuhn, Birgit Vogler, Jana Schramm, Mary Oram, Wolfgang Schösser, and Gerald Kramp for excellent technical assistance.

The authors declare no competing financial interests.

${ }^{*}$ D.Y.K., C.A., and T.H. share senior authorship. 
role of BACE1 in the insidious cognitive decline of AD patients, studies on BACE1 knock-out (KO) mice have revealed a number of physiological functions of BACE1 in the nervous system (Yan, 2017). BACE1-deficient mice display hyperactivity, seizures, memory deficits, schizophrenia-like endophenotypes, and, notably, neurodegeneration with age (Vassar et al., 2014). At the cellular level, the enzyme has been implicated in various aspects of brain development and function, axon guidance, myelination, spine density, and synaptic transmission (Munro et al., 2016). Adding further complexity to our understanding of its physiological effects, BACE1 is also capable of regulating neuronal excitability (Kim et al., 2007; Hitt et al., 2010; Hu et al., 2010). Altered cleavage of auxiliary subunits of voltage-dependent ion channels has been proposed as an underlying mechanism (Kim et al., 2007; 2011; Sachse et al., 2013). Recently, our group showed that BACE1 regulates neuronal excitability also through direct, nonenzymatic interactions with voltage-dependent $\mathrm{Na}^{+}$channels, as well as with voltage-dependent $\mathrm{K}^{+}$channels of the KCNQ (Kv7) family, as reviewed in Lehnert et al. (2016).

In general, levels of BACE1 in the brain are high during development and then decline as the brain matures (Willem et al., 2006). However, there is a remarkable exception to this rule, namely the mossy fiber (MF) pathway in the hippocampus, where BACE1 levels remain elevated into adulthood (Laird et al., 2005; Kandalepas et al., 2013). The MF tract is formed by nonmyelinated axons of dentate gyrus granule cells projecting to pyramidal cells and interneurons of the CA3 region (Bischofberger et al., 2006). The MF synapse is a key connection within the hippocampal circuit that is thought to play important roles in complex neuronal computations such as pattern separation and completion during memory formation and recall (Bischofberger et al., 2006). The presynaptic terminals form large boutons and display pronounced presynaptic plasticity (Bischofberger et al., 2006). MF boutons (MFBs) are endowed with a number of unique electrophysiological features that make the synapse a "conditional detonator," meaning that, with repetitive activation, it becomes strong enough to elicit action potentials in the CA3 neuron (Bischofberger et al., 2006; Kerr and Jonas, 2008).

To secure high temporal precision of synaptic transmission at the MF synapse, the presynaptic action potential has to be repolarized rapidly to restrict $\mathrm{Ca}^{2+}$ influx and subsequent glutamate release (Bischofberger et al., 2006). Combined evidence from immunohistochemistry and from patch-clamp recordings of MFBs advanced Kv3.4 channels as prime candidates to keep presynaptic action potentials short (Chang et al., 2007; Prüss et al., 2010; Alle et al., 2011).

In general, $\mathrm{Kv} 3$ channels are predominantly located in axons and terminals, where they generate high-threshold $\mathrm{K}^{+}$currents with fast activation and deactivation kinetics (Ishikawa et al., 2003; Goldberg et al., 2005; Alle et al., 2011; Rowan et al., 2016). With these features, Kv3 channels are perfectly tuned to enable rapid action potential repolarization and high-frequency firing (Rudy and McBain, 2001; Ritter et al., 2015). Unlike Kv3.1 and Kv3.2, which are specifically expressed in hippocampal fastspiking interneurons, Kv3.3 and, more so, Kv3.4 display fast inactivation, suggesting that they are a major constituent of the transient (A-type) $\mathrm{K}^{+}$currents at MFBs (Chang et al., 2007; Alle

Correspondence should be addressed to either Christian Alzheimer or Tobias Huth, Institute of Physiology and Pathophysiology, Friedrich-Alexander-Universität Erlangen-Nürnberg, Universitätsstr. 17, 91054 Erlangen, Germany, E-mail: christian.alzheimer@fau.de or tobias.huth@fau.de.

DOI:10.1523/JNEUROSCI.2643-17.2018

Copyright $\odot 2018$ the authors $\quad 0270-6474 / 18 / 383481-15 \$ 15.00 / 0$ et al., 2011; Kaczmarek and Zhang, 2017). In the mouse hippocampus, sorting of Kv3.4 channels to MF axons starts in the second postnatal week, whereas Kv3.4 immunoreactivity in granule cell somata ceases at the same postnatal stage (Prüss et al., 2010).

In view of the remarkably parallel enrichment of the mature MF tract in BACE1 and Kv3.4, we wondered whether BACE1 plays a role in channel expression and function. We report here that BACE1 enhances surface levels of Kv3.4 and targets them to presynaptic terminals, thereby strengthening the impact of the channel on signal transmission at the MF synapse. Mechanistically, BACE1 was found to augment Kv3.4 currents through a direct, nonenzymatic interaction with the channel protein.

\section{Materials and Methods}

Animals. BACE1 KO mice (BACE1 ${ }^{\text {tm1Psa }}$ ) had been generated by insertion of a neo expression cassette from pMC1neopA into exon 1 of Bace1, introducing a premature translational stop codon into the open reading frame (Dominguez et al., 2005). Mice had ad libitum access to food and water. Housing, feeding, breeding, and handling of the mice were according to federal guidelines with the approval of the local government. Immunofluorescence, electrophysiological, and trafficking experiments were performed with mice of either sex of BACE $1^{\text {tmlPsa }}$. A second BACE1 KO strain (BACE1 ${ }^{\text {tm1Pcw }}$ ) had been generated similarly (Cai et al., 2001) and mice were kindly provided by Prof. Mark W. Albers of Harvard Medical School (Cao et al., 2012). BACE1 ${ }^{\mathrm{tm} 1 \mathrm{Pcw}}$ were further bred and housed with ad libitum access to food and water and all animal husbandry and experimental procedures were approved by the Massachusetts General Hospital Subcommittee on Animal Research Care and conform to the National Institutes of Health guidelines of the care and use of laboratory animals. Hippocampal slice biotinylation and hippocampal synaptic fractionation experiments were performed with mice of either sex of BACE $1^{\text {tmlPcw }}$. Genotyping of both strains was done by PCR amplification at postnatal days 10-21.

NB-360 BACE inhibitor treatment. One-month-old male and female C57BL/6 mice (Charles River Laboratories) were fed food pellets containing the BACE inhibitor NB-360 (0.3 g/kg, Novartis; Neumann et al., 2015) or control pellets for 4 weeks. Phenotypically, oral BACE inhibitor treatment was associated with fur depigmentation, which can be related to inhibition of BACE in melanocytes (Shimshek et al., 2016).

Plasmids. The following DNA constructs were used in this work: pmCherry-N1 (Clontech); pEGFP-C1 (U55763.1; Clontech); hKv3.4 (BC101769.1; Harvard PlasmID Database) and hKv3.4 fused to EGFP; hBACE1 (NM_012104.4) and hBACE1 fused to EGFP; and hENaC1 $\alpha$ (NM_001038.5, see Agsten et al., 2015) fused to mCherry (from pmCherryN1). All vectors were based on pcDNA3.1 (Thermo Fisher Scientific), if not stated otherwise.

Antibodies. The following antibodies were used in this work: rabbitanti-Kv3.4 (APC-019; Alomone Laboratories), mouse-anti-Kv3.4 (75-112; NeuroMab), rabbit-anti-BACE1 (ab108394; Abcam), goat-anti-BACE1 (ab11028; Abcam), rabbit-anti-BACE (D10E5, 5606; Cell Signaling Technology), rabbit-anti-pan-cadherin (4068; Cell Signaling Technology), rabbit-anti$\mathrm{Na}^{+}-\mathrm{K}^{+}$-ATPase $\alpha 1$ (3010; Cell Signaling Technology), rabbit-anti-V5 (ab9116; Abcam), goat-anti-HA (ab9134; Abcam), mouse-anti- $\beta$-actinHRP (A3854; Sigma-Aldrich), goat-anti-CNTN2 (AF4439; R\&D Systems), mouse-anti- $\mathrm{K}_{\mathrm{Ca}} 1.1$ (ab192759; Abcam), rabbit-anti-K $\mathrm{Ca}^{2.3}$ (APC-025; Alomone Laboratories), rabbit-anti-synapsin-1 XP (D12G5, 5297; Cell Signaling Technology), mouse-anti-PSD-95 (75-028; NeuroMab), mouse-anti-NR2B (73-097/73-101; NeuroMab), rabbit-anti-APP (C66; Bhattacharyya et al., 2013), goat-anti-rabbit-HRP (ab6721; Abcam), rabbit-anti-goat-HRP (ab6741; Abcam), rabbit-anti-mouse-HRP (ab6728; Abcam), donkey-anti-rabbit-HRP (NA934; GE Healthcare), sheep-anti-mouse-HRP (NA931; GE Healthcare), donkey-anti-goatHRP (705-035-147; Jackson Laboratories), mouse-anti-rabbit-HRP (188816-31, TrueBlot; Rockland), IRDye 680RD goat-anti-mouse IgG (P/N 926-68070; LI-COR), IRDye 800CW donkey-anti-rabbit IgG (P/N 92632213; LI-COR), goat-anti-mouse-Alexa Fluor 488 (A-11029; Invitrogen), and goat-anti-rabbit-Cy3 (111-165-144; Dianova). 
Cell culture and transient transfection. HEK293T cells (CRL-11268; ATCC; www.atcc.org, kindly provided by Prof. Michael Stürzl, FriedrichAlexander-Universität Erlangen-Nürnberg, Erlangen, Germany) were cultured in Dulbecco's modified Eagle's medium ( $1 \mathrm{~g} / \mathrm{L}$ glucose, L-glutamine, sodium bicarbonate, and phenol red; Sigma-Aldrich) supplemented with $10 \%$ fetal bovine serum (FBS Superior; Merck) and $1 \%$ penicillin/streptomycin (Sigma-Aldrich). Cells were split every 3-4 d using Accutase (Sigma-Aldrich). Cells were transfected using JetPEI (Polyplus-transfection). For electrophysiological recordings, $2.5^{\star} 10^{5}$ HEK293T cells were plated on $35 \mathrm{~mm}$ dishes (BD Biosciences) $1 \mathrm{~d}$ before transfection and transfected with 75-250 ng of DNA of EGFP, $150 \mathrm{ng}$ of $\mathrm{Kv} 3.4$, and $500 \mathrm{ng}$ of BACE1. For surface biotinylation assay and coimmunoprecipitation (co-IP) experiments, $2^{\star} 10^{6}$ HEK293T cells were plated on $100 \mathrm{~mm}$ dishes (BD Biosciences) and transfected after $1 \mathrm{~d}$ with 375 ng of EGFP, 750 ng of Kv3.4, and 2500 ng of BACE1. For Fluorescence recovery after photobleaching experiments (FRAP), HEK293T cells were plated onto $1.5 \mathrm{H}$ coverslips (VWR) and transfected the following day with $450 \mathrm{ng}$ of mCherry, $450 \mathrm{ng}$ of $\mathrm{Kv} 3.4$, or $450 \mathrm{ng}$ of $\mathrm{ENaCl} \alpha$ mCherry and $150 \mathrm{ng}$ of BACE1-EGFP.

Immunofluorescence in hippocampal slices. One-month-old mice were deeply anesthetized with sevoflurane (AbbVie), intraperitoneally injected with ketamine (Pfizer)/xylazin (Bayer), and transcardially perfused with $20 \mathrm{ml}$ of $0.9 \% \mathrm{NaCl}$ (B. Braun) and $20 \mathrm{ml}$ of $2-4 \%$ paraformaldehyde (Carl Roth). Mice were decapitated and brains were dissected and stored in PBS (Sigma-Aldrich) for $24 \mathrm{~h}$ at $4^{\circ} \mathrm{C}$. PBS was replaced by $30 \%$ sucrose (Sigma-Aldrich) in PBS for $24 \mathrm{~h}$ at $4^{\circ} \mathrm{C}$. Brains were embedded in Tissue-Tek O.C.T. Compound (Sakura) and rapidly frozen in methylbutane (Carl Roth). Next, $14 \mu \mathrm{m}$ coronal hippocampal sections were cut using a Leica cryostat (CM3050 S), mounted on polyL-lysine-coated slides (R. Langenbrinck), and stored at $-20^{\circ} \mathrm{C}$. For staining, slices were thawed for $1 \mathrm{~h}$ and rehydrated by washing with PBS for 5 $\mathrm{min}$. Slices were blocked and permeabilized for $1 \mathrm{~h}$ with $5 \%$ normal goat serum (Dianova) in PBT [PBS, 1\% BSA (Sigma-Aldrich), and 0.5\% Triton X-100 (Sigma-Aldrich)]. Samples were washed in PBS for $5 \mathrm{~min}$. Primary antibodies diluted in PBT (rabbit-anti-Kv3.4 1:500, mouseanti-Kv3.4 1:200, rabbit-anti-BACE1; Abcam, 1:200) were incubated overnight at room temperature. The next day, samples were washed 3 times with PBS for 5 min each with gentle shaking. Secondary antibodies diluted in PBT (goat-anti-mouse-Alexa Fluor 488, 1:2000; goat-antirabbit-Cy3, 1:1000) were incubated for $1 \mathrm{~h}$ at room temperature. Samples were washed three times with PBS and mounted with Roti-Mount FluorCare DAPI (Carl Roth). Imaging was performed on a Confocal LSM780 (Zeiss) with an inverse stage Axio Observer.Z1 and an EC PlanNeofluar $10 \times / 0.30$ or Plan-Apochromat $63 \times / 1.40$ oil differential interference contrast (DIC) objective. Alexa Fluor 488 and Cy3 were excited at 488 and $561 \mathrm{~nm}$, respectively.

Hippocampal slice biotinylation. One-month-old mice were deeply anesthetized by isoflurane (Butler Schein) and decapitated. The procedure was performed as described in Kim and Kovacs (2011) with the following modifications: Transverse $400 \mu \mathrm{m}$ hippocampal slices were prepared on a vibratome (DTK-1500E; Ted Pella). Slices were biotinylated with $0.3 \mathrm{mg} / \mathrm{ml}$ biotin (EZ-Link Sulfo-NHS-LC-Biotin; Pierce) in constantly gassed Earle's Balanced Salt Solution (EBSS with sodium bicarbonate, without phenol red; Sigma-Aldrich) on ice for $45 \mathrm{~min}$ in the dark. Hippocampi of individual slices were dissected manually using a scalpel and magnifier glass (6×; Eschenbach) and hippocampal tissue of all slices of one mouse was pooled, snap frozen on dry ice, and stored at $-20^{\circ} \mathrm{C}$ until protein extraction. To obtain equal biotinylation conditions, one WT and one BACE1 KO mouse were dissected and biotinylated in parallel at the same day and further considered as experimental pair. Protein extraction was performed in a lysis buffer containing $10 \mathrm{~mm}$ Tris-HCl (pH 6.8; Gentrox), 2 mm EDTA (Sigma-Aldrich), $150 \mathrm{~mm} \mathrm{NaCl}$ (Thermo Fisher Scientific), 0.2\% SDS (American Bioanalytical), 0.5\% sodium deoxycholate (Sigma-Aldrich), 1\% Triton X-100 (Roche), $1 \mathrm{~mm}$ 1-10-phenanthroline (ICN Biochemicals), 1 mm phenylmethylsulfonylfluorid (Sigma-Aldrich), cOmplete MINI EDTA-free protease inhibitor mixture (Roche), and phosphatase inhibitor mixture (Thermo Fisher Scientific). For biotinylation samples, $200 \mu \mathrm{g}$ of protein $(1 \mu \mathrm{g} / \mu \mathrm{l}$ in lysis buffer) were captured overnight by $30 \mu \mathrm{l}$ of NeutrAvidin beads (Pierce) that had been washed in lysis buffer. Proteins were eluted at $95^{\circ} \mathrm{C}$ for 5 min in $65 \mu \mathrm{l}$ of loading buffer containing MES SDS running buffer (Thermo Fisher Scientific), LDS sample buffer (Thermo Fisher Scientific), and $2 \% \beta$-mercaptoethanol (Sigma-Aldrich). Then, $20 \mu \mathrm{l}$ of biotinylated protein and $15 \mu \mathrm{g}$ of total protein were loaded for SDS-PAGE/ Western blot.

Synaptic fractions. One-month-old WT and BACE1 KO mice were sacrificed by $\mathrm{CO}_{2}$ inhalation, decapitated, and hippocampi were dissected. Alternatively, 2-month-old mice that had been treated with the BACE inhibitor NB-360 and control pellets were deeply anesthetized by isoflurane inhalation (CP-Pharma), decapitated, and hippocampi were dissected. Synaptic fractions were prepared according to the manufacturer's protocol (Syn-PER Synaptic Protein Extraction Reagent; Thermo Fisher Scientific). Protein concentration of all fractions was measured using BCA Protein Assay Kit (Pierce). Protein was either prepared in loading buffer containing MES SDS running buffer (Thermo Fisher Scientific),LDSsamplebuffer(ThermoFisherScientific), and $2 \% \beta$-mercaptoethanol (Sigma-Aldrich), or in Syn-PER buffer, loading buffer (ProSieve ProTrack Dual Color Loading Buffer; Lonza), and $100 \mathrm{~mm}$ dithiothreitol (DTT; Sigma-Aldrich). For SDS-PAGE/Western blot, $25 \mu \mathrm{g}$ of protein for homogenate and synaptic fraction and $20 \mu \mathrm{g}$ for cytosolic fraction obtained from WT and BACE1 KO mice or $10 \mu \mathrm{g}$ of synaptic and $7 \mu \mathrm{g}$ of cytosolic protein prepared from BACE inhibitor-treated mice and controls were used.

Co-IP. Co-IP was conducted at $4^{\circ} \mathrm{C}$ using ice-cold solutions. Two days after transfection, cells were pelleted and three equally transfected 100 $\mathrm{mm}$ dishes were pooled for further analysis. Cells were resuspended in lysis buffer [50 mM Tris-HCl, pH 7.4; Sigma-Aldrich), $150 \mathrm{~mm} \mathrm{NaCl}$ (Carl Roth), 2 mм EDTA (Carl Roth), 1\% NP-40 (Sigma-Aldrich), 1\% Triton X-100 (Sigma-Aldrich), and cOmplete MINI EDTA-free protease inhibitor mixture (Roche)]. Lysates were sonicated for 5 min using a water bath ultrasonic device (VWR), incubated on ice for $30 \mathrm{~min}$, sonicated for another $5 \mathrm{~min}$, and centrifuged at $6000 \times \mathrm{g}$ for $10 \mathrm{~min}$. The supernatant was diluted 1:5 in PBS (Sigma-Aldrich) supplemented with protease inhibitor mixture. Protein concentration was measured using BCA Protein Assay Kit (Pierce). For total cell lysate samples, protein was prepared in lysis buffer 1:5 diluted with PBS supplemented with protease inhibitor mixture (further referred to as diluted lysis buffer), loading buffer (ProSieve ProTrack Dual Color Loading Buffer; Lonza), and 100 mм DTT (Sigma-Aldrich). For immunoprecipitation, $500 \mu \mathrm{g}$ of protein $(1 \mu \mathrm{g} / \mu \mathrm{l}$ in diluted lysis buffer) was incubated overnight with $1.5 \mu \mathrm{g}$ of antibody (goat-anti-BACE1, rabbit-anti-Kv3.4) in an orbital shaker. For isotype controls, goat-anti-HA or rabbit-anti-V5 antibody was used. In addition, control samples with $500 \mu \mathrm{g}$ of protein but without antibody or samples with antibody but without protein were prepared. Protein G agarose beads (Pierce) were washed in diluted lysis buffer and blocked overnight in 1\% BSA (Sigma-Aldrich) in an orbital shaker. The next day, BSA was replaced by diluted lysis buffer. Then, $40 \mu \mathrm{l}$ of Protein G bead solution was added to each sample and incubated for $1 \mathrm{~h}$ at room temperature in an orbital shaker. Samples were washed three times in diluted lysis buffer. Captured proteins were eluted from the beads by incubating $65 \mu \mathrm{l}$ of diluted lysis buffer with loading buffer and $100 \mathrm{~mm} \mathrm{DTT} \mathrm{at} 95^{\circ} \mathrm{C}$ for $5 \mathrm{~min}$. Then, $15 \mu \mathrm{l}$ of eluted protein and $10 \mu \mathrm{g}$ of total protein were loaded for SDS-PAGE/Western blot. To avoid antibody bands of denatured IP-antibody to interfere with co-IP signal, we used the mouse-antirabbit-HRP secondary antibody that detects native instead of denatured antibody preferentially.

Cell surface biotinylation assay. Cell surface biotinylation experiments were conducted $2 \mathrm{~d}$ after transfection as described previously in Hessler et al. (2015). Selected cells were treated with $5 \mu \mathrm{M}$ InSolution $\beta$-Secretase Inhibitor IV (Merck) directly after transfection for a total of $2 \mathrm{~d}$. Medium and inhibitor were exchanged after $1 \mathrm{~d}$. Cells without inhibitor were treated equally with $0.1 \%$ DMSO (Sigma-Aldrich).

SDS-PAGE and Western blot. Samples were heated at $95^{\circ} \mathrm{C}$ for $5 \mathrm{~min}$. Proteins were separated in 10\% TGX stain-free precast gels (Bio-Rad) or $4-12 \%$ Bis-Tris Protein Gels (Thermo Fisher Scientific) and transferred onto PVDF membranes (Bio-Rad), iBlot 2 Transfer Stacks (Thermo Fisher Scientific) using a wet (Criterion Blotter; Bio-Rad) or dry (iBlot 2 Dry Blotting System; Thermo Fisher Scientific) blotting system. After 
blocking in 5\% skim milk (Carl Roth, LabScientific) or 4\% donkey serum (Sigma-Aldrich) in TBS-T (10 mm Tris-HCl; Sigma-Aldrich), $150 \mathrm{~mm}$ $\mathrm{NaCl}$ (Carl Roth), 0.1\% Tween 20 (Carl Roth or Boston BioProducts), primary antibodies were incubated overnight at $4^{\circ} \mathrm{C}$ in TBS-T with $1-4 \%$ BSA (Sigma-Aldrich) or $4 \%$ donkey serum and $0.1 \% \mathrm{NaN}_{3}$ (SigmaAldrich). After washing in TBS-T, membranes were incubated with secondary antibody coupled to horseradish peroxidase (HRP) or fluorescent dye in $5 \%$ milk or $4 \%$ donkey serum in TBS-T or blocking buffer (Odyssey; LI-COR), respectively, for $1 \mathrm{~h}$ at room temperature. The signal was visualized by enhanced chemiluminescence (ECL) using ECL Western Blotting Substrates (Pierce; Bio-Rad) or by fluorescence and imaged using the ChemoStar Imager (INTAS) or the Odyssey Imaging System (LI-COR). Membranes were stripped in $6 \mathrm{M}$ guanidine- $\mathrm{HCl}$ (Carl Roth), $20 \mathrm{~mm}$ Tris (Sigma-Aldrich), 0.2\% Triton X-100 (Sigma-Aldrich), pH 7.5 , and $0.8 \% \beta$-mercaptoethanol (Carl Roth) for $20 \mathrm{~min}$ at room temperature or in $62.5 \mathrm{~mm}$ Tris-HCl, pH 6.8 (Gentrox), 2\% SDS (American Bioanalytical), and $0.75 \% \beta$-mercaptoethanol (Sigma-Aldrich) for $15 \mathrm{~min}$ at $55^{\circ} \mathrm{C}$. After blocking, blots were reprobed. For densitometric analysis, Fiji software (Schindelin et al., 2012) with the Bio-Formats plugin (Linkert et al., 2010) was used.

Electrophysiological slice recordings. Twenty-two to 27-d-old mice were deeply anesthetized with sevoflurane (AbbVie), decapitated, and transverse hippocampal slices $(350 \mu \mathrm{m})$ were prepared in ice-cold artificial CSF (aCSF) containing a high concentration of sucrose and the following (in mM) (Sigma-Aldrich): 75 sucrose, $87 \mathrm{NaCl}, 2.5 \mathrm{KCl}, 0.5 \mathrm{CaCl}_{2}, 7$ $\mathrm{MgCl}_{2}, 1.25 \mathrm{NaH}_{2} \mathrm{PO}_{4}, 25 \mathrm{NaHCO}_{3}$, and $10 \mathrm{D}(+)$-glucose. Slices were kept at room temperature for at least $2 \mathrm{~h}$ in aCSF solution containing the following (in mM): $125 \mathrm{NaCl}, 3 \mathrm{KCl}, 0.5 \mathrm{CaCl}_{2}, 3.5 \mathrm{MgCl}_{2}, 1.25 \mathrm{NaH}_{2} \mathrm{PO}_{4}, 25$ $\mathrm{NaHCO}_{3}$, and $10 \mathrm{D}(+)$-glucose. Individual slices were transferred to a submerged recording chamber (perfused with aCSF containing $2.5 \mathrm{~mm}$ $\mathrm{CaCl}_{2}$ and $1.5 \mathrm{~mm} \mathrm{MgCl}_{2}$ at $32^{\circ} \mathrm{C}$ ) that was mounted on the stage of an upright microscope. All solutions were gassed with $95 \% \mathrm{O}_{2} / 5 \% \mathrm{CO}_{2}$. Recording pipettes were filled with modified aCSF in which $\mathrm{NaHCO}_{3}$ was replaced with HEPES (12.5 mM HEPES and $12.5 \mathrm{~mm}$ Na-HEPES; Sigma-Aldrich). Constant current pulses (width $0.1 \mathrm{~ms}$, applied at 0.1 $\mathrm{Hz}$ ) were delivered to a bipolar platinum electrode, carefully positioned in the granule cell layer/hilus to evoke MF field EPSPs (MF-fEPSP) in CA3 stratum lucidum. In some experiments, a new recording pipette containing the potassium channel blockers 4-aminopyridine (4-AP; Sigma-Aldrich) or blood-depressing substance-I (BDS-I; Alomone Laboratories) in pipette solution was carefully reinserted along the previous track. The group II metabotropic glutamate receptor agonist DCG IV ( $3 \mu \mathrm{M}$; Tocris Bioscience) was applied at the end of some recordings to verify MF origin. Field potentials were filtered at $2 \mathrm{kHz}$ and sampled at $20 \mathrm{kHz}$ using a Multiclamp 700B amplifier in conjunction with a Digidata 1440A interface and pClamp10 software (all from Molecular Devices). Data analysis was performed offline with Clampfit software (Molecular Devices).

Electrophysiology of transfected cell line cells. HEK293T cells were recorded 40-48 h after transfection and identified by their green fluorescence using an inverted fluorescence microscope (Axiovert35; Zeiss) equipped with a $10 \times$ objective (Achroplan, $0.03 \mathrm{~W}$; Zeiss) and a $40 \times$ objective with Hoffmann modulation contrast (HMC40 LWD $0.5 \mathrm{nu}-$ merical aperture, NA) with a fiber-optic-coupled light source (HXP 120C; Zeiss) with high-quality filter set for GFP (AHF Analysetechnik) used to excite EGFP. Whole-cell recordings were performed at $20 \pm 1{ }^{\circ} \mathrm{C}$. Borosilicate glass electrodes with filament (BioMedical Instruments) were pulled on a DMZ-Universal Puller (Zeitz) with a tip resistance in bath solution of 2.2-3.5 M $\Omega$ and attached to a microelectrode holder connected to a preamplifier (Headstage CV-7B patch-clamp for MultiClamp 700B; Molecular Devices) and Axopatch 700B amplifier in conjunction with a Digidata 1322A interface and pClamp10 software (all from Molecular Devices). Series resistance compensation was $\geq 75 \%$. Recordings were sampled at $20 \mathrm{kHz}$ and filtered at $6 \mathrm{kHz}$. Experiments were started 2 min after whole-cell access was established. Patch electrodes were filled with a pipette solution containing the following (in mм) (Sigma-Aldrich): 135 potassium gluconate, 5 HEPES, $3 \mathrm{MgCl}_{2}$, 5 EGTA, $2 \mathrm{Na}_{2}$-ATP, $0.3 \mathrm{Na}_{3}$-GTP, and $4 \mathrm{NaCl}$ adjusted to $\mathrm{pH} 7.25$ with $\mathrm{KOH}$ (Carl Roth). Cells were kept in bath solution containing the following (in mM) (Sigma-Aldrich): $145 \mathrm{NaCl}, 4 \mathrm{KCl}, 2 \mathrm{MgCl}_{2}, 2 \mathrm{CaCl}_{2}, 10$
HEPES, and $10 \mathrm{D}(+)$-glucose, adjusted to $\mathrm{pH} 7.4$ with $\mathrm{NaOH}$ (Merck). Data analysis was performed using the pClamp10 software (Molecular Devices). All currents were leak-corrected offline. To determine voltagedependent activation, the conductance $(G)$ was calculated from steadystate activation protocol by the equation $G=I /\left(V-E_{\mathrm{K}}{ }^{+}\right)$, where $I$ is the average peak current, $V$ the applied voltage, and $E_{K}^{+}$the equilibrium potential for $\mathrm{K}^{+}$ions under our experimental conditions. $G$ was fitted by a standard sigmoidal relation (Boltzmann) of the form $G(V)=\left(A_{1}-A_{2}\right)$ ) $\left(1+\exp \left(\left(V-V_{1 / 2}\right) / d_{V}\right)\right)+A_{2}$ with the $A_{1}$ lower asymptote corresponding to the minimal conductance, the $A_{2}$ upper asymptote corresponding to the maximal conductance, $V_{1 / 2}$ being the voltage at half maximal conductance, and $d_{V}$ the slope factor in $V_{1 / 2}$. The average peak values were divided by $A_{2}$ for normalization. For calculating the voltagedependent inactivation, current amplitudes of each recording from testpulses, which followed prepulses of $-60 \mathrm{mV}$ to $+20 \mathrm{mV}$ recorded with the inactivation protocol, were fitted with a standard sigmoidal relation (Boltzmann). Peak current values from $-120 \mathrm{mV}$ to $+20 \mathrm{mV}$ were normalized to the upper asymptote. Time constants of activation and inactivation were simultaneously estimated from the activation protocol with use of a biexponential function with the first cursor positioned at $10 \%$ of the rising phase and the second cursor positioned at $40 \%$ current in the falling phase. Statistical significance of time constants was tested on logarithmically transformed data. For illustration, time constant mean \pm SEM were back-transformed to a linear scale.

Immunofluorescence and trafficking in cultured hippocampal neurons. Hippocampal neuronal cultures were prepared and transfected as described previously in Welzel et al. (2010). Two- to 5-d-old WT mice were sacrificed by decapitation. Hippocampi were dissected, pooled from two animals, and cut into smaller pieces in HBSS (Invitrogen) supplemented with 20\% FBS (Merck). Tissue pieces were digested for 5 min using 5 $\mathrm{mg} / \mathrm{ml}$ trypsin (Sigma-Aldrich) in digestion solution containing the following (in mM) (Carl Roth): $137 \mathrm{NaCl}, 5 \mathrm{KCl}, 7 \mathrm{Na}_{2} \mathrm{HPO}_{4}$, and 25 HEPES adjusted to $\mathrm{pH} 7.2$ with $\mathrm{NaOH}$. Cell dissociation was performed by mechanical trituration in $12 \mathrm{~mm} \mathrm{MgSO}_{4}$ (Carl Roth) in HBSS. Then, a $50 \mu \mathrm{l}$ suspension of hippocampal cells was plated on $18 \mathrm{~mm}$ coverslips (Marienfeld-Superior) coated with 2\% Growth Factor Reduced Matrigel (Corning) in $950 \mu \mathrm{l}$ of MEM (Invitrogen) supplemented with 10\% FBS, $5 \mathrm{~g} / \mathrm{L}$ glucose (Carl Roth), $0.2 \mathrm{~g} / \mathrm{L} \mathrm{NaHCO}_{3}$ (Carl Roth), $0.1 \mathrm{~g} / \mathrm{L}$ transferrin (Sigma-Aldrich), $0.025 \mathrm{~g} / \mathrm{L}$ insulin (Sigma-Aldrich), and $2 \mathrm{~mm}$ L-glutamin (Sigma-Aldrich) to attain an appropriate cell density. The following day, half of the medium was removed and $1 \mathrm{ml}$ of maintenance MEM was supplemented with 5\% FBS, 2\% B27-Supplement (Invitrogen), $1 \times$ penicillin/streptomycin, $5 \mathrm{~g} / \mathrm{L}$ glucose, $0.2 \mathrm{~g} / \mathrm{L} \mathrm{NaHCO}_{3}, 0.1 \mathrm{~g} / \mathrm{L}$ transferrin, $0.5 \mathrm{~mm}$ L-glutamin, and $6 \mu \mathrm{M}$ cytosine arabinoside (SigmaAldrich) was added to the cells. Cells were cultured in a humid environment. After $3 \mathrm{~d}$ in vitro (DIV), a calcium-phosphate-mediated transfection was performed. Each well was transfected with $1.25 \mu \mathrm{g}$ of endotoxin-free (EndoFree Maxi Preparations; Qiagen) Kv3.4-EGFP DNA, BACE1 DNA, or empty vector. The culture medium was removed, stored, and replaced with Neurobasal A medium (Invitrogen). DNA was mixed with $250 \mathrm{~mm}$ $\mathrm{CaCl}_{2}$ in a total volume of $25 \mu \mathrm{l}$. Then, $25 \mu \mathrm{l}$ of transfection buffer containing the following (in mM) (Sigma-Aldrich): 10 HEPES, $280 \mathrm{NaCl}$, and $1.5 \mathrm{Na}_{2} \mathrm{HPO}_{4}$ adjusted to $\mathrm{pH} 7.05$ with $\mathrm{NaOH}$ was added and incubated for $30 \mathrm{~min}$. Next, $450 \mu \mathrm{l}$ of Neurobasal A medium was applied to the calcium phosphate/DNA precipitate and incubated for $30 \mathrm{~min}$ with the transfection mixture on the cells. Cultures were washed in HBSS and maintained in the original culture medium.

Immunofluorescence experiments were performed at 6-7 DIV. Cells were washed twice with PBS (Sigma-Aldrich), incubated with methanol for $10 \mathrm{~min}$ at $-20^{\circ} \mathrm{C}$, and washed again in PBS. Cells were permeabilized and blocked at room temperature for $30 \mathrm{~min}$ with $5 \%$ normal goat serum (Dianova) in PBT [PBS, 1\% BSA (Sigma-Aldrich), 0.5\% Triton X-100 (Sigma-Aldrich) ]. Primary antibodies diluted in PBT (mouse-anti-Kv3.4 1:200, rabbit-anti-BACE1; Abcam, 1:200) were incubated for $2 \mathrm{~h}$ at room temperature. Afterward, samples were washed 3 times with PBS for $5 \mathrm{~min}$ each with gentle shaking and secondary antibodies diluted in PBT (goatanti-mouse-Alexa Fluor 488 1:2000; goat-anti-rabbit-Cy3 1:1000) were incubated for $1 \mathrm{~h}$ at room temperature. Samples were washed three times with PBS and mounted with Roti-Mount FluorCare DAPI (Carl Roth). 
A

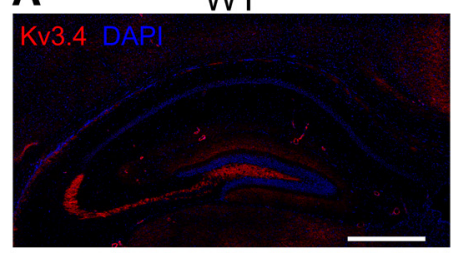

B
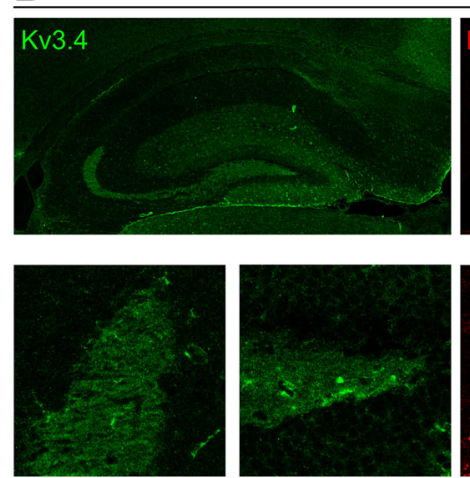

C
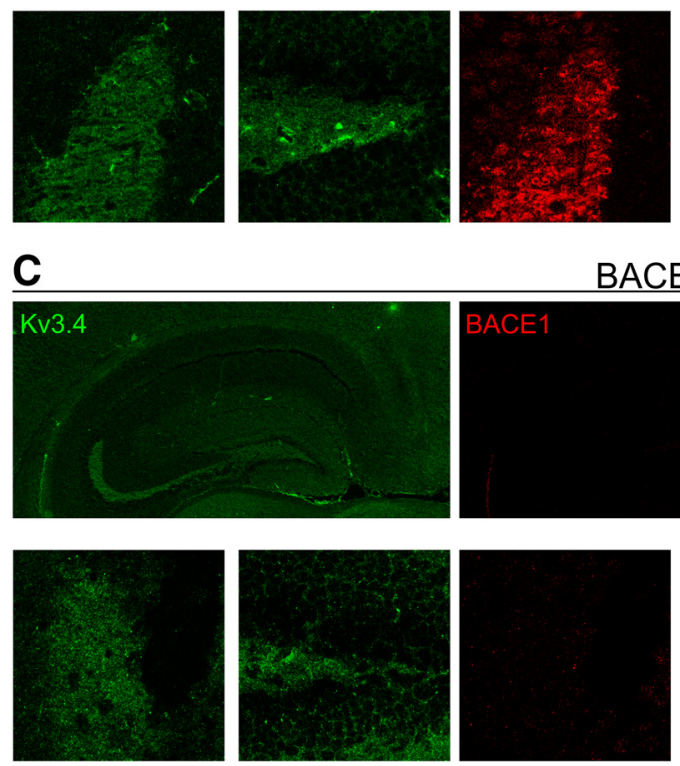

BACE1 KO

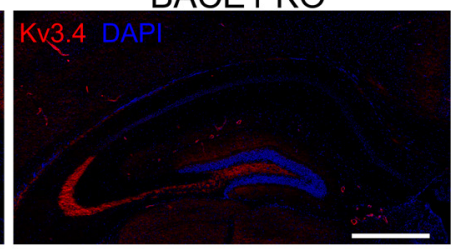

WT
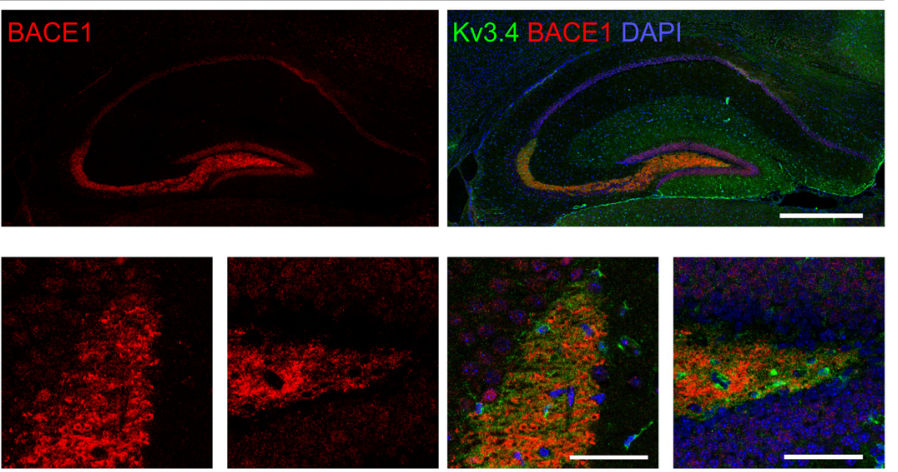

BACE1 KO
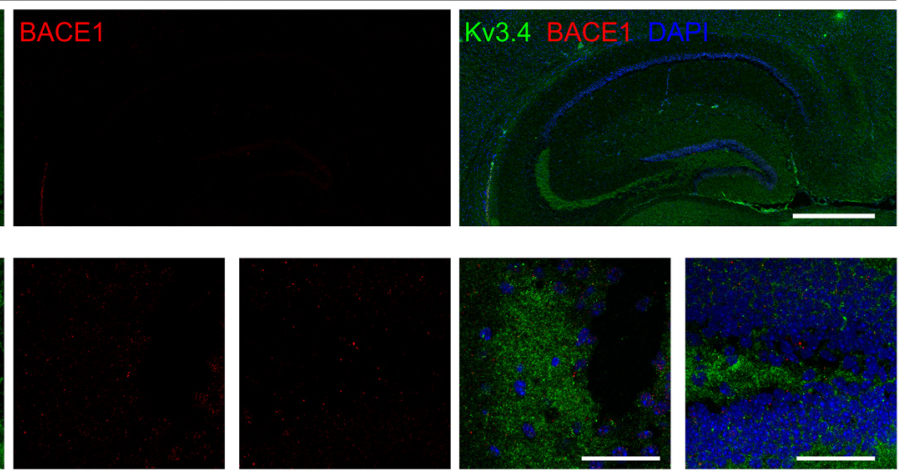

Figure 1. BACE1 and Kv3.4 colocalize in the MF pathway of the hippocampus. A, Immunofluorescence staining showing prominent Kv3.4 signal in the hilar region and in the MF tract. Staining was performed with the rabbit-anti-Kv3.4 antibody and DAPI in 1-month-old BACE1 WT (left, $n=5$ ) and KO (right, $n=4$ ) mice. Scale bar, $500 \mu \mathrm{m}$. B, Double staining for Kv3.4 (left, mouse-anti-Kv3.4 antibody) and BACE1 (middle, rabbit-anti-BACE1 antibody; Abcam) with superposition of images (right) shows a distinct colocalization in the hippocampus of 1-month-old BACE1 WT mice. Scale bar, $500 \mu \mathrm{m}$. Higher-magnification images below show the hilar region (right) and the end of the MF tract (left), $n=3$. Scale bar, $50 \mu \mathrm{m}$. C, Double staining of Kv3.4 and BACE1 with higher-magnification images as described in $\boldsymbol{B}$ for hippocampal slices of age-matched $\mathrm{KO}$ mice, $n=3$. Scale bars as in $\boldsymbol{B}$.

Imaging was performed on a Confocal LSM780 (Zeiss) with an inverse stage Axio Observer.Z1 and a Plan-Apochromat $63 \times / 1.40$ Oil DIC objective. Alexa Fluor 488 and Cy3 were excited at 488 and $561 \mathrm{~nm}$, respectively.

For trafficking analysis, hippocampal neurons were imaged at 6-8 DIV in HBS adjusted to $\mathrm{pH}$ 7.4. Time-lapse imaging was performed at $37^{\circ} \mathrm{C}$ with a Yokogawa CSU-X1 5000 spinning disk confocal device on a Zeiss Axio Observer Z1 inverted microscope equipped with a $63 \times$ PlanApochromat, 1.4 NA objective. EGFP was excited with a $488 \mathrm{~nm}$ laser and fluorescence was collected using a 525/50 emission filter. Images were captured with an Evolve 512 EMCCD camera (Photometrics). Axons were identified by length and diameter. Time series were sampled every $530 \mathrm{~ms}$ with $500 \mathrm{~ms}$ exposure time for 700 frames in total. Bleaching was performed for 350 frames with maximum laser power. The cultures were used for imaging no longer than $75 \mathrm{~min}$. Kymographs were generated from time stacks with Fiji software (Schindelin et al., 2012) using the Bio-Formats (Linkert et al., 2010), NeuronJ (Meijering et al., 2004) and MultipleKymograh (J. Rietdorf and A. Seitz) plugin. Vesicle trajectories were analyzed computer assisted. Each trajectory was traced once from its first appearance to change in slope.

FRAP. FRAP experiments were performed $1-2 \mathrm{~d}$ after transfection of HEK293T cells as described previously in Agsten et al. (2015). Quantifi- cation was done using Zen2010 software (Zeiss). Statistical significance of time constants was tested on logarithmically transformed data. For illustration, time constant mean \pm SEM were back-transformed to a linear scale.

Experimental design and statistical analysis. Data analysis and statistics were performed using OriginPro version 9.0 (OriginLab) and GraphPad Prism 6 software. Numbers are given as mean \pm SEM, if not stated otherwise. Normal distribution was tested using the Shapiro-Wilk test. Numbers and replicates and tests to determine statistical significance are stated in text and figure legends of the respective experiments.

\section{Results}

BACE1 and Kv3.4 colocalize in the MF pathway of the hippocampus

Within the hippocampal network of 1-month-old WT and BACE1 KO animals, prominent Kv3.4 immunofluorescence was observed in the hilus of the dentate gyrus and in stratum lucidum of the CA4-CA3 region (Fig. $1 A$ ), consistent with previous reports that Kv3.4 is sorted to MF axons (Chang et al., 2007; Prüss et al., 2010). To analyze colocalization of BACE1 and Kv3.4, we performed double stainings in brain slice preparations of the 

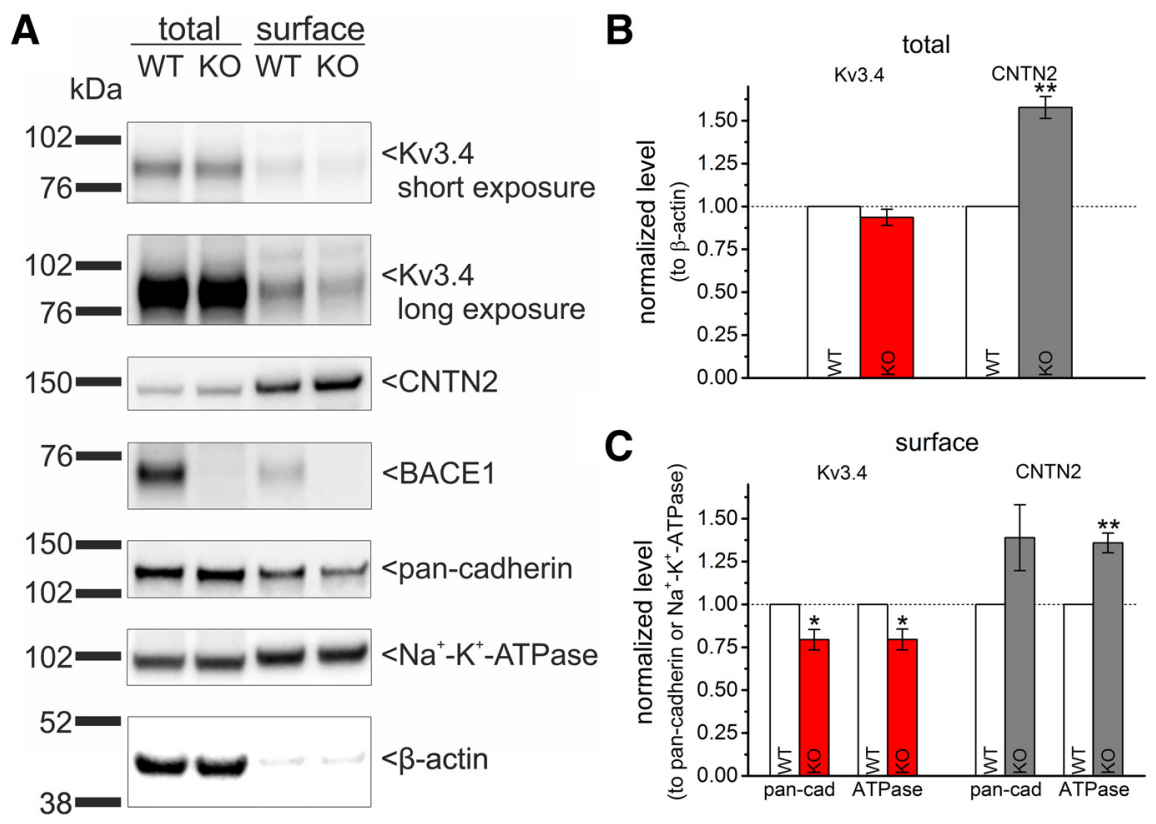

Figure 2. Kv3.4 surface levels are reduced in the hippocampus of BACE1 K0 mice. $A$, Representative Western blot of a hippocampal slice biotinylation for a WT/KO set. $\boldsymbol{B}$, Total protein levels were densitometrically quantified, normalized to $\beta$-actin, and each K0 sample was normalized to the corresponding WT that had been set to 1. Red column shows total Kv3.4 protein in K0 and results for the positive control CNTN2 are illustrated in the gray column. C, Surface proteins were quantified and normalized to the corresponding levels of pan-cadherin or $\mathrm{Na}^{+}-\mathrm{K}^{+}$-ATPase and $\mathrm{KO}$ samples were normalized to WT according to $\boldsymbol{B}$. Results of $\mathrm{KO}$ mice reveal a significant decrease in surface level for Kv3.4 (red columns) and a significant increase for CNTN2 (gray columns). WT $/ K 0, n=4$ pairs, ${ }^{*} p<0.05,{ }^{* *} p<0.01$, two-tailed one-sample $t$ test.

same age group (Fig. $1 B, C$ ). In this set of experiments, we used a second, mouse-derived Kv3.4 antibody, which produced a very similar staining pattern for Kv3.4 as the rabbit-derived antibody used in the above experiment (cf. Fig. $1 B, C$, left, $1 A$ ). Highmagnification images (Fig. $1 B, C$, bottom) demonstrated strong Kv3.4 signals in the hilus (Fig. $1 B, C$, right) and the CA3 stratum lucidum (Fig. $1 B, C$, left). Staining with a BACE1 antibody in WT hippocampus yielded the characteristic expression pattern with prominent immunofluorescence signals being confined to the MF tract (Fig. 1B, middle) (Laird et al., 2005; Zhao et al., 2007; Kandalepas et al., 2013). No specific BACE1 signal was detectable in $\mathrm{KO}$ littermates (Fig. 1C, middle). Superposition of the images showed the remarkable and site-specific overlap of BACE1 and Kv3.4 in the MF pathway of WT hippocampi (Fig. $1 B$, right).

\section{Kv3.4 surface levels are reduced in the hippocampus of BACE1 KO}

To determine whether BACE1 affects total or surface levels of $\mathrm{Kv} 3.4$ protein in hippocampus, we performed slice biotinylation experiments using 1-month-old WT and BACE1-deficient mice. A representative Western blot for total and surface proteins of a $\mathrm{WT} / \mathrm{KO}$ set is depicted in Figure $2 A$. Total proteins were normalized to the corresponding $\beta$-actin signal and each $\mathrm{KO}$ was normalized to its respective WT that had been set to 1 (Fig. $2 B$ ). The absence or presence of BACE1 had no significant effect on total Kv3.4 protein $(p=0.27)$ (Fig. $2 B)$. The BACE1 substrate contactin-2 (CNTN2) (Kuhn et al., 2012; Gautam et al., 2014) served as a positive control, showing a significant increase of $58 \%$ in fulllength total protein $(p=0.0029)$ in hippocampi from BACE1 KO mice (Fig. 2B).

Surface proteins were quantified and determined comparable to total levels with normalization to the surface marker cadherin or $\mathrm{Na}^{+}-\mathrm{K}^{+}$-ATPase (Fig. 2C) (Hessler et al., 2015). Although not affecting total Kv3.4 protein in the hippocampus, BACE1 deficiency was associated with a significant decrease in the surface expression of the channel (normalized to pancadherin $p=0.041, \mathrm{Na}^{+}-\mathrm{K}^{+}$-ATPase $p=$ 0.044 ), which attained $80 \%$ of the level detected in WT hippocampus (Fig. 2C). As expected, surface levels of CNTN2 fulllength protein were substantially increased in BACE1 ${ }^{-1-}$ hippocampi by $39 \%$ when normalized to pan-cadherin $(p=0.14)$ and by $36 \%$ with normalization to $\mathrm{Na}^{+}-\mathrm{K}^{+}$-ATPase $(p=0.0083)$ (Fig. 2C).

\section{BACE1 alters Kv3.4 axonal trafficking in cultured hippocampal neurons}

Given that Kv3.4 is sorted to MF axons and terminals, we next investigated whether BACE1 and Kv3.4 are present in the same vesicles along axons and if BACE1 plays a role in the axonal trafficking of Kv3.4. BACE1 itself was recently shown to be preferentially targeted to axons and to be present in large stationary structures representing presynaptic sites (Buggia-Prévot et al., 2014; Das et al., 2016; Ye et al., 2017). Immunofluorescence staining in cultured hippocampal neurons of BACE1 WT or KO pups, which were transfected with Kv3.4-EGFP and BACE1 after 3 DIV, was used to examine the axonal localization of the two proteins. Supporting their co-trafficking, we observed colocalization of Kv3.4-EGFP and BACE1 in punctate vesicular-like structures in all imaged axons (Fig. $3 A$ ). We did not detect any difference in the expression pattern or protein localization between the two genotypes. Furthermore, with time-lapse imaging, we analyzed and compared the motion of vesicles containing Kv3.4 in axons of cultured hippocampal neurons from WT and BACE1 KO mice which were or were not cotransfected with BACE1 3-5 d before. Compared with published data and our own data (not shown) on BACE1-EGFP-puncta (Buggia-Prévot et al., 2014; Das et al., 2016), fluorescence intensity of Kv3.4EGFP vesicles was relatively weak indicating a low vesicle load. Kymographs of axonal Kv3.4-EGFP dynamics rather resemble kymographs of YFP-Kv1.2 movement (Gu and Gu, 2010). Single axons were imaged and kymographs were generated (Fig. 3B). Changes in fluorescence intensity along the axon over time indicate axonal vesicular trafficking and the velocity distributions are illustrated in a cumulative probability plot (Fig. $3 C, D$ ). The velocities of anterograde and retrograde transport were in the range of average transport rates reported for fast axonal transport (WT: Kv3.4-EGFP: median anterograde $1.5 \mu \mathrm{m} / \mathrm{s}$; median retrograde 1.4 $\mu \mathrm{m} / \mathrm{s}$; Hirokawa et al., 2010). Comparing hippocampal cultures from BACE1 KO and WT revealed that endogenous BACE1 levels had no significant impact on Kv3.4-EGFP trafficking (KO: Kv3.4-EGFP: median anterograde $1.4 \mu \mathrm{m} / \mathrm{s}$; median retrograde: $1.4 \mu \mathrm{m} / \mathrm{s}$ ). In contrast, in either preparation, overexpression of BACE1 significantly reduced the number of fast Kv3.4-EGFPcontaining vesicles in both transport directions as indicated by the deviation of the curves beyond $2 \mu \mathrm{m} / \mathrm{s}$ in the cumulative probability plots (Fig. 3C, KO data not shown). This effect was 
A
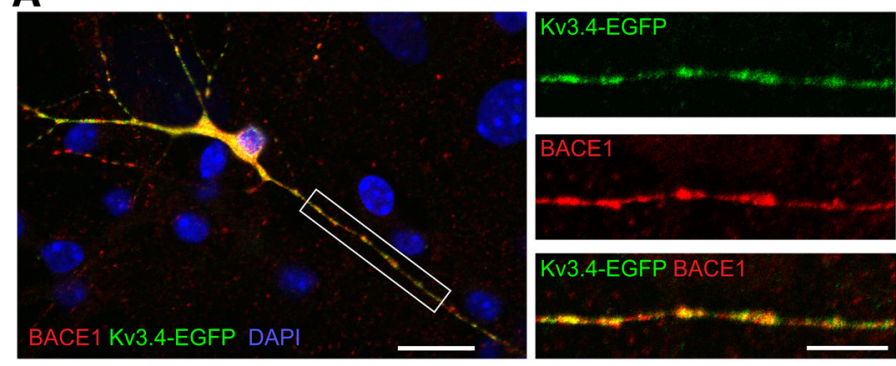

Kv3.4-EGFP
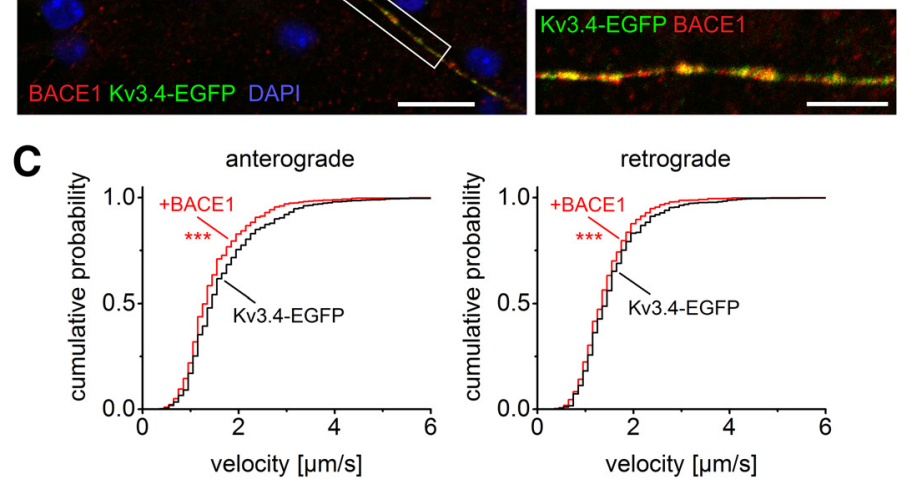

D
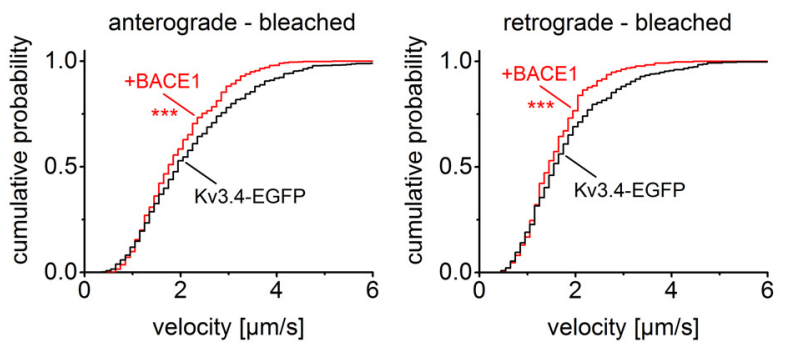

B

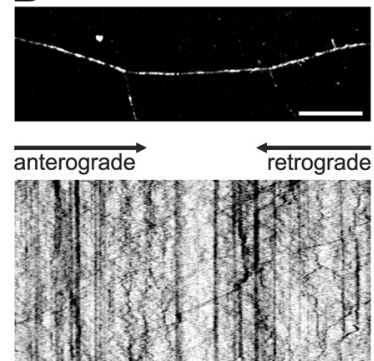

bleached
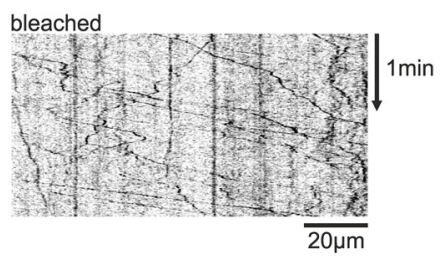

Figure 3. BACE1 alters Kv3.4 trafficking in cultured hippocampal neurons. $A$, Left, Immunofluorescence double staining in a hippocampal neuron obtained from WT transfected with Kv3.4-EGFP and BACE1 (left: green, mouse-anti-Kv3.4 antibody; red, rabbit-anti-BACE1 antibody; Abcam; and DAPI). Scale bar, $20 \mu \mathrm{m}$. Right, Higher-magnification images of the indicated region along the axon. Scale bar, $10 \mu \mathrm{m}$. WT, $n=8$ axons; K0, $n=3$ axons. Double staining was performed in transfected hippocampal neurons at $6-7$ DIV in three independent WT and two K0 cultures. $\boldsymbol{B}-\boldsymbol{D}$, Axonal transport of Kv3.4-EGFP in transfected hippocampal neurons of WT was imaged at $6-8$ DIV. Images were sampled every 530 ms for 6 min before and after bleaching the axonal segment. $\boldsymbol{B}$, This frame of an image series shows an axon (top) and a representative part of the corresponding kymographs before (middle) and after bleaching (lower). $\boldsymbol{C}, \boldsymbol{D}, \mathbf{G r a p h s}$ demonstrating the cumulative probabilities for velocities of Kv3.4-EGFP vesicles moving in anterograde or retrograde direction depending on BACE1 coexpression (anterograde: Kv3.4-EGFP, $n=863,+$ BACE1, $n=788$; bleached: Kv3.4-EGFP, $n=680,+$ BACE1, $n=565$; retrograde: Kv3.4-EGFP, $n=875,+$ BACE1, $n=810 ;$ bleached: $n=378,+$ BACE1, $n=346)$. Data were obtained from three independent cultures. ${ }^{* * *} p<0.001$, two-tailed Mann-Whitney test applied to all unbinned vesicle velocities.

even more pronounced when we bleached the axons before imaging (Fig. 3D). Bleaching shifted analysis toward the faster vesicular fraction and improved visualization of single vesicles ( $\mathrm{Gu}$ and $\mathrm{Gu}, 2010$ ). These results demonstrate that BACE1 is able to modulate Kv3.4 axonal trafficking.

\section{BACE1 $^{-/-}$mice show reduced Kv3.4 protein in hippocampal synapses}

To evaluate the synaptic protein level of Kv3.4, we prepared hippocampal fractions from both lines of mice, which were, again, 1 month of age. Figure $4 A$ shows the Western blot of synaptic fractions and, for comparison, of total and cytosolic protein, from three WT and three $\mathrm{KO}$ animals. In addition to Kv3.4, the fractions were also stained for the $\mathrm{Ca}^{2+}$-activated $\mathrm{K}^{+}$channels $\mathrm{K}_{\mathrm{Ca}} 2.3$ and $\mathrm{K}_{\mathrm{Ca}} 1.1$, which are both present in MFBs (Trimmer, 2015). To assess the purity of the synaptic fractions, we checked the expression of the following three synaptic markers: presynaptic protein synapsin-1, postsynaptic density protein 95 (PSD-95), and NMDA-receptor subunit NR2B. Compared with the cytosolic fraction, all three markers were clearly enriched in synaptic fractions (Fig. 4A). For densitometric analysis, signals from the synaptic fractions were normalized to $\beta$-actin. Consistent with the results from the slice biotinylation assay (Fig. 2), we observed a significant increase in CNTN2 in BACE1-deficient hippocampi
(133\%, $p=0.0036)$, whereas Kv3.4 was decreased to $76 \%$ of its synaptic level in WT hippocampi $(p=0.048)$. Importantly, genetic disruption of Bacel was not associated with changes in the synaptic levels of $\mathrm{K}_{\mathrm{Ca}} 2.3(p=0.92)$ and $\mathrm{K}_{\mathrm{Ca}} 1.1(p=0.44)$. We also found no significant differences in total $\mathrm{K}^{+}$channel levels between the two groups (data not shown).

\section{NB-360 BACE inhibitor-treated mice show no significant decrease in Kv3.4 levels at hippocampal synapses} We next investigated whether Kv3.4 synaptic protein levels depend on BACE1 enzymatic activity. To address this issue in a physiological setting, we fed 1-month-old C57BL/6 mice food pellets containing the functionally validated BACE inhibitor NB360 (Neumann et al., 2015; Keskin et al., 2017; Peters et al., 2018) or control pellets for 4 weeks and prepared hippocampal fractions as described above. Figure $5 \mathrm{~A}$ depicts a representative Western blot of cytosolic and synaptic protein, which, again, shows an enrichment of the synaptic markers synapsin-1 and PSD-95 in the respective fractions (Fig. 5A). We did not detect changes in synaptic proteins between treated animals and controls. Accumulation of full-length protein of the BACE1 substrates APP $(154 \%, p=$ $0.0075)$ and CNTN2 $\left(147 \%, p=1.9^{*} 10^{-5}\right)$ confirmed potent inhibition of BACE1 activity in NB-360-treated mice. Interestingly, pharmacological inhibition of BACE1 produced a stronger in- 

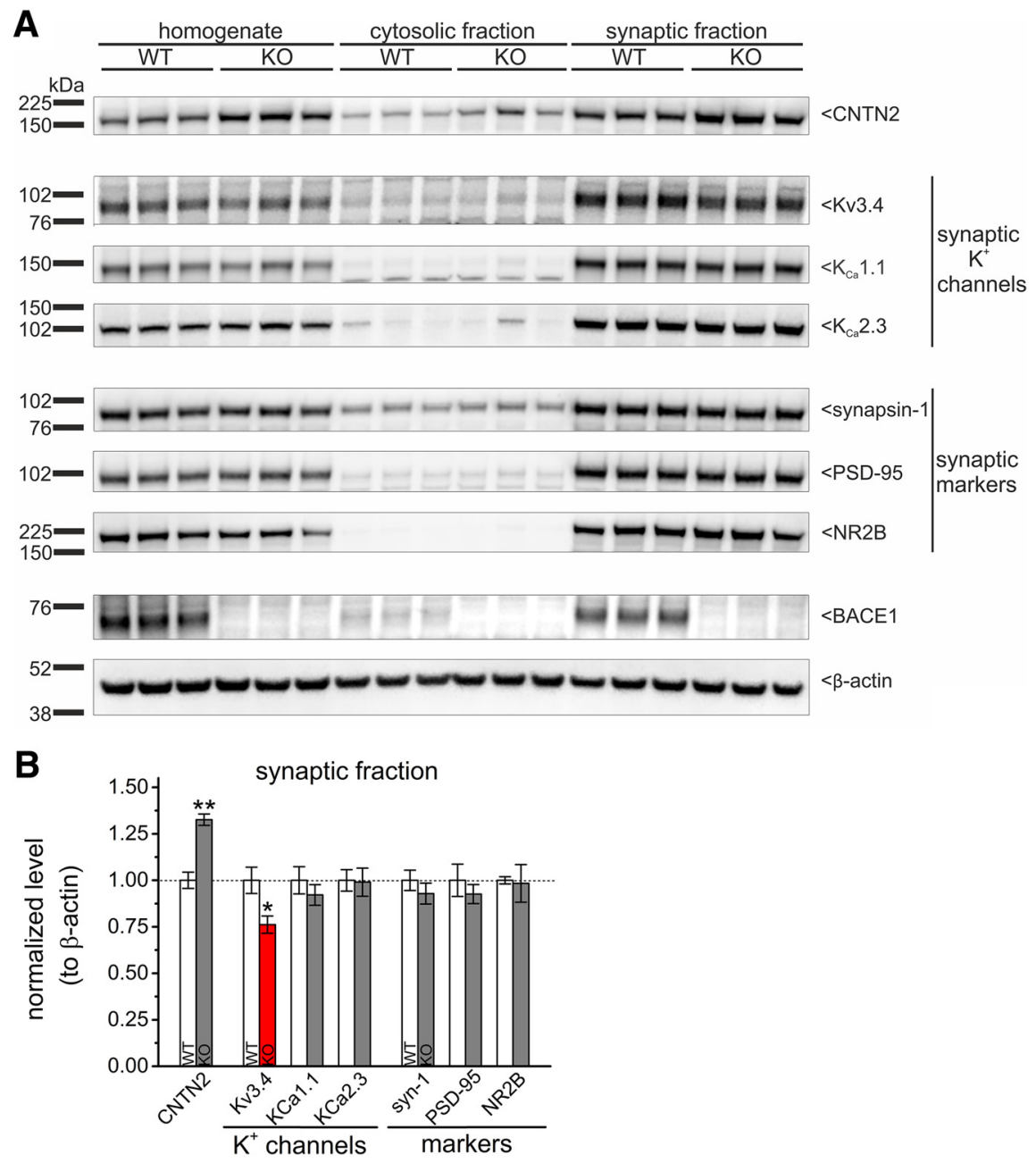

Figure 4. BACE1-null mice show reduced Kv3.4 level in hippocampal synapses. $A$, Representative Western blot of hippocampal fractions showing total, cytosolic, and synaptic fraction of 1-month-old BACE1 WT and K0 mice. $B$, Synaptic level of the indicated proteins was quantified and normalized to corresponding $\beta$-actin levels. WT (white columns) was set to 1 for illustration. The red column shows the $\mathrm{KO}$ result for Kv3.4, the gray columns for other synaptic $\mathrm{K}^{+}$channels and synaptic markers. $n=3$ for each genotype, ${ }^{*} p<0.05,{ }^{* *} p<0.01$, two-tailed two-sample $t$ test.

crease in CNTN2 (Fig. 5B) than genetic deletion of Bace1 (Fig. $4 B)$. The apparent small decrease in Kv3.4 levels did not reach significance compared with untreated controls $(82 \%, p=0.11$; Fig. $5 B, C$ ), demonstrating that $\mathrm{Kv} 3.4$ deficit at the MF synapse in BACE1 KO is not mediated by BACE1 enzymatic activity. The slight reduction in Kv3.4 levels in some NB-360-treated animals might be due to a concomitant decrease in BACE1 expression given the strong correlation between BACE1 and synaptic Kv3.4 expression in these animals (Pearson's $r=0.79$; Fig. $5 D$ ). In control animals, the BACE1 levels were homogenous and did not show such a correlation (Pearson's $r=-0.04$ ).

\section{Reduced Kv3 current leads to altered synaptic transmission in BACE1 KO}

Because activation of Kv3 currents has been identified as the prevailing mechanism to curtail the width of presynaptic action potentials (see Introduction), we next investigated whether the decrease of synaptic Kv3.4 protein in BACE1-deficient hippocampi would alter the basic properties of this synapse. To address this question, we stimulated the MF pathway and recorded MF-fEPSP in stratum lucidum of area CA3 using hippocampal slices from 22- to 27-d-old WT and BACE1 $1^{-1-}$ mice. We first determined the input/output (I/O) relationship of the MF synapse in the two populations. When we plotted MF-fEPSP amplitude as a function of stimulus intensity, we obtained a significant shift of the I/O curve toward lower amplitudes in mutant hippocampi (Fig. 6A). At first, this seemed a perplexing finding because, if anything, a decrease in presynaptic Kv3.4 should have enhanced MF-EPSPs. However, when we added the transient $\mathrm{K}^{+}$current blocker 4 -AP $(100 \mu \mathrm{M})$ or the specific Kv3 current blocker BDS-I $(30 \mu \mathrm{M})$ to the pipette solution, we observed a significantly different effect of the blockers on the I/O curves between WT and mutant preparations (Fig. $6 B-D$ ). Whereas 4-AP and BDS-I both produced a pronounced upward shift of the I/O curve of the MF synapse in WT hippocampi, the excitatory effect of the two blockers was significantly weaker in BACE1-deficient hippocampi (Fig. 6B$D)$. At a stimulation intensity of $150 \mu \mathrm{A}$, 4-AP enhanced MF-fEPSPs to $140 \pm 7 \%$ of control in WT hippocampi and to $119 \pm 2 \%$ of control in BACE1-deficient hippocampi $(p=0.042)$. Lending support to the notion that $\mathrm{Kv} 3$ carries most of the repolarizing current (Alle et al., 2011), BDS-I increased MF-fEPSP to $133 \pm 5 \%$ of control in WT slices and to $119 \pm 3 \%$ of control in BACE $1^{-/-}$slices $(p=0.044)$. Although BDS-I should selectively suppress presynaptic Kv3 channels in axons and terminals of MFs, a number of presynaptic and postsynaptic changes might, in principle, affect our electrophysiological read-out; that is, the MF-fEPSP. We therefore also analyzed fiber volleys, which reflect action potential firing of MF axons. Recordings without inhibitor did not reveal differences in fiber volleys, indicating that basic axonal excitability is not altered between the genotypes (Fig. $6 \mathrm{~A}$, inset). In contrast, at a stimulation intensity of $150 \mu \mathrm{A}$, BDS-I indeed produced a significantly stronger enhancement of the fiber volley in WT hippocampi (112 $\pm 2 \%)$ compared with BACE1-deficient mice (105 $\pm 1 \%, p=0.0040$; Fig. $6 D)$. Application of 4-AP showed the same tendency to enhance fiber volleys preferentially in WT hippocampi, but, due to a larger variation, the drug response did not reach significance ( $p=0.34$; Fig. $6 D$ ). These data underscore that the interaction between BACE1 and Kv3.4 should occur at the presynaptic site and result in functional consequences for basic synaptic transmission.

A characteristic feature of the MF-CA3 pyramidal cell synapse is the strong amplification of EPSPs during repetitive stimulation (Bischofberger et al., 2006). To quantify the facilitation during a train of five stimuli at $20 \mathrm{~Hz}$, we normalized peak MF-fEPSP amplitudes to the first response (Fig. $6 E$, inset). Although the MF synapse in BACE1-deficient hippocampus showed a depressed I/O relationship compared with its WT counterpart, short-term facilitation in the mutant slice exceeded by far that of control (Fig. $6 E)$. To determine whether Kv3 current contributes to the regulation of short-term plasticity, we repeated the experiment with 
A

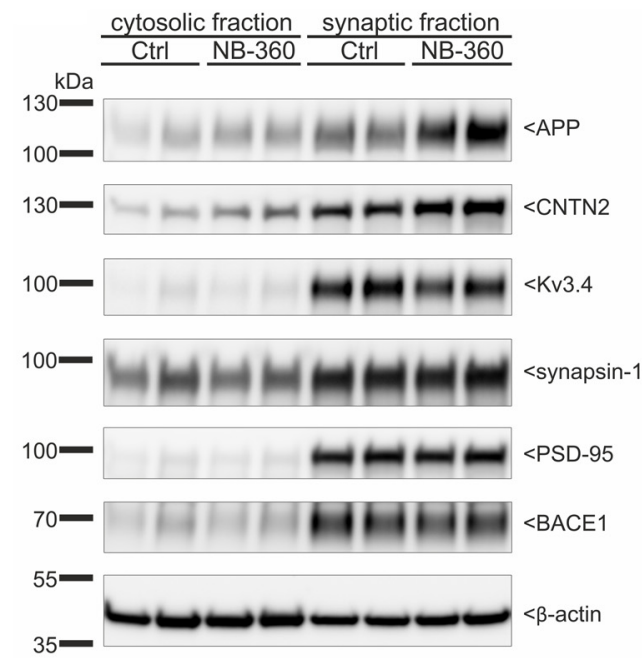

B

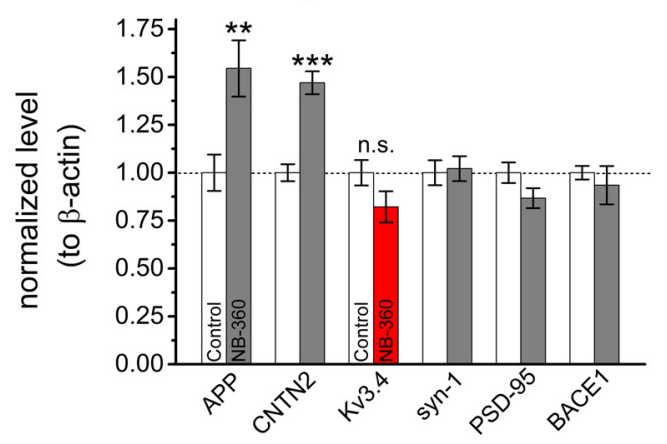

synaptic fraction

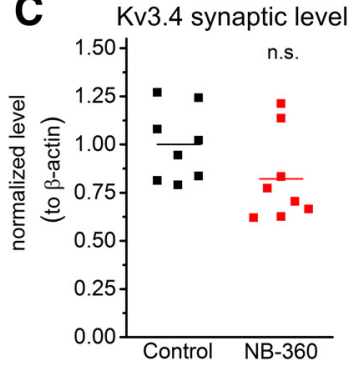

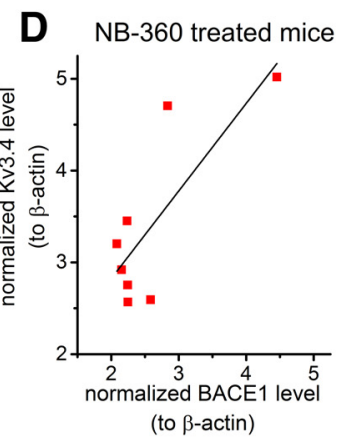

Figure 5. Mice treated with the BACE inhibitor NB-360 show no significant decrease in Kv3.4 levels at hippocampal synapses. A, Representative Western blot of hippocampal fractions showing cytosolic and synaptic proteins of 2-month-old C57BL/6 mice, which were fed food pellets containing BACE inhibitor NB-360 or control pellets for 4 weeks. B, Synaptic level of the indicated proteins quantified and normalized to the corresponding $\beta$-actin levels. Untreated controls (white columns) were set to 1 for illustration. Red column shows Kv3.4 results from treated mice. Gray columns depict results for the BACE1 substrates CNTN2 and APP, synaptic marker proteins synapsin-1 and PSD-95, and for BACE1 protein in NB-360-fed mice. C, Scatter plot demonstrating the synaptic protein level of Kv3.4 for each investigated animal. Bar indicates mean. D, Correlation analysis of BACE1 versus Kv3.4 expression. Pearson's $r=0.79 . n=8$ for treatment and control group, ${ }^{* *} p<0.01$, ${ }^{* * *} p<0.001$. n.s., Not significant, two-tailed two-sample $t$ test.

BDS-I $(30 \mu \mathrm{M})$ in the pipette solution. Although the drug diffused out of the pipette and increased the postsynaptic response, stimulus intensity was adjusted to keep amplitude of first MFfEPSP in stimulus train constant. The facilitation curves of Figure $6 F$ show that pharmacological suppression of Kv3 current failed to affect short-term plasticity of MF-fEPSPs in either preparation.

\section{BACE1 amplifies Kv3.4 current and alters channel kinetics in} a heterologous expression system

To gain insight into the mechanism underlying the presumed interaction between BACE1 and Kv3.4 channels, we explored the effects of BACE1 on Kv3.4 channel gating in HEK293T cells transiently overexpressing Kv3.4 with or without BACE1. In wholecell voltage-clamp recordings, Kv3.4 channels showed typical A-type current kinetics with fast activation and inactivation and a small fraction of noninactivating current in response to depolarizing voltage steps (Fig. 7A1). Coexpression of BACE1 produced a massive increase of Kv3.4 currents (Fig. 7A2) leading to a pronounced upward shift of the $I-V$ relationship (Fig. $7 C$ ). The strong enhancement of Kv3.4 current by cotransfection of BACE1 was reproduced in another expression system ( $\mathrm{CHO}$ cells; data not shown). In addition to boosting Kv3.4 currents over the entire voltage range of activation, BACE1 significantly lowered the activation time constants (Fig. $7 F$ ) and increased the inactivation time constants measured at 0 and $+10 \mathrm{mV}$ (Fig. $7 F$ ). Moreover, BACE1 significantly fastened the recovery time from channel inactivation (Fig. 7G). BACE1 did not shift the voltage dependence of activation (Fig. $7 E, V_{1 / 2}: \mathrm{Kv} 3.415 .0 \pm 1.0 \mathrm{mV}$, + BACE1 $12.5 \pm 1.3 \mathrm{mV}$ ), nor did it alter the voltage dependence of steadystate inactivation, which was determined from the current responses depicted in Figure 7, B1 and B2 $\left(V_{1 / 2}:\right.$ Kv3.4 - $17.7 \pm 0.7$
$\mathrm{mV},+$ BACE1 $-15.9 \pm 0.7 \mathrm{mV}$; Fig. $7 E$ ). Steady-state inactivation of Kv3.4 channels showed a steep voltage dependence between -60 and $+20 \mathrm{mV}$, whereas a second inactivation process with a much more shallow voltage dependence seemed to regulate the availability of Kv3.4 channels at membrane potentials negative to $-70 \mathrm{mV}$ (Fig. $7 E$ ). The apparent dichotomy of steadystate inactivation was supported by the observed plateau reached by the available fraction at $\sim-60 \mathrm{mV}$ in almost all recordings, which also excluded rundown. This profile was also observed in the steady-state inactivation described previously by Fineberg et al. (2012). Interestingly, coexpression of BACE1 did not only produce a huge amplification of the transient current, but also enhanced the fraction of current which did not inactivate during sustained depolarization (Fig. $7 B$ ). When quantified at a test potential of $+30 \mathrm{mV}$, BACE1 almost doubled the noninactivating component $\left(p=7.5^{\star} 10^{-6}\right.$; Fig. $\left.7 D\right)$. We next used an action potential waveform to activate Kv3.4 current in HEK293T cells (Fig. 7H). Consistent with its important role in action potential repolarization (Riazanski et al., 2001; Kaczmarek and Zhang, 2017), Kv3.4 current peaked in the repolarizing phase of the voltage trajectory (Fig. $7 \mathrm{H}$ ). Overexpression of BACE1 strongly augmented Kv3.4 current during membrane repolarization (Fig. $7 \mathrm{H}, \mathrm{I}$ ). Again, this finding was reproduced in CHO cells (data not shown).

\section{BACE1 interacts directly with Kv3.4}

The results shown in Figure 5 argued for a direct, nonproteolytic interaction between BACE1 and Kv3.4. To determine the physical association between the two proteins in more detail, we performed co-IP and FRAP experiments in transfected HEK293T cells. We were indeed able to coimmunoprecipitate Kv3.4 with BACE1 and vice versa (Fig. 8A,B). Controls with protein and 
A input-output relationship

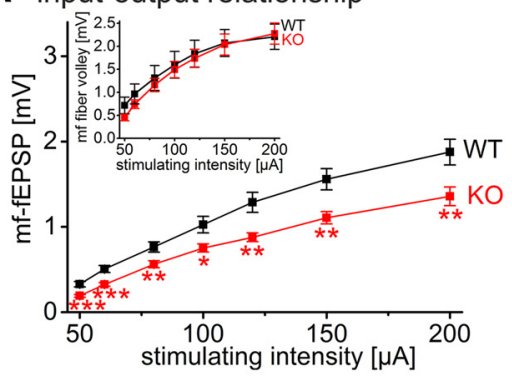

C BDS-I in recording pipette

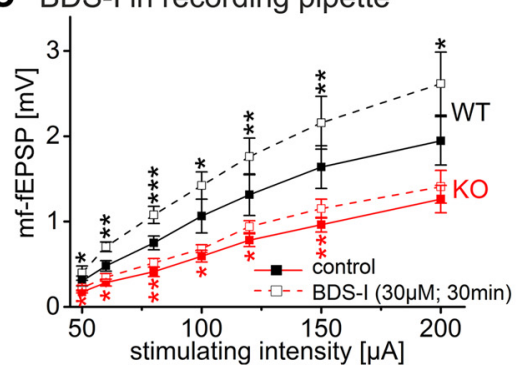

E train stimuli at $20 \mathrm{~Hz}$

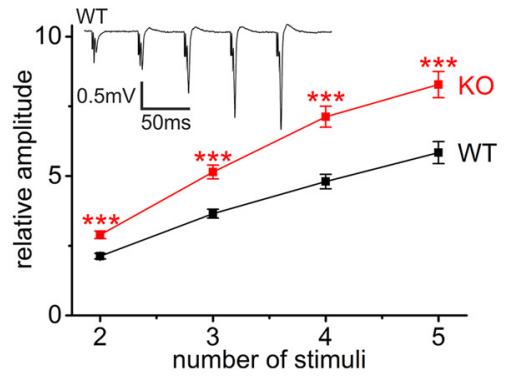

B 4-AP in recording pipette

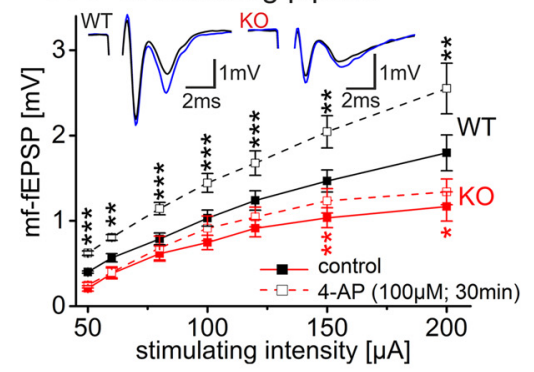

D

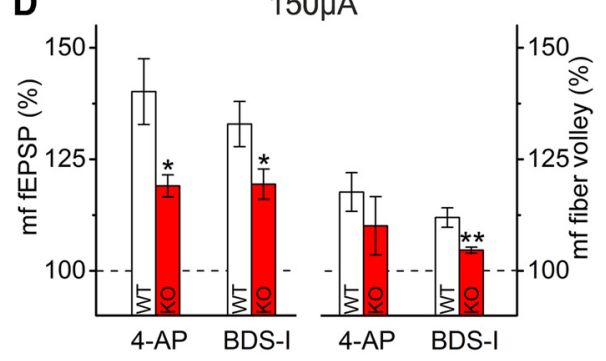

F $\quad$ BDS-I in recording pipette

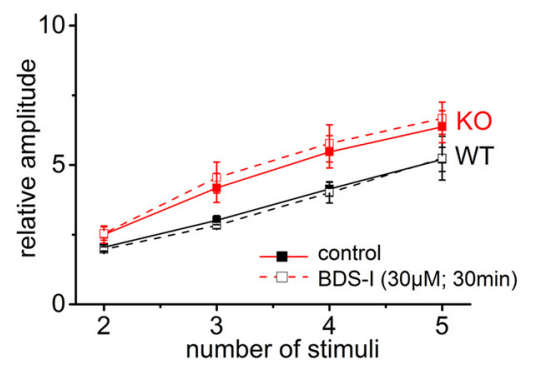

Figure 6. Reduced Kv3 current leads to altered synaptic transmission in BACE1 KO. A, MFs from BACE1 K0 mice manifested a reduced I/O relationship for MF-fEPSP. Peak amplitudes were plotted as a function of stimulus intensity. Corresponding fiber volley amplitudes are depicted in the inset. WT, $n=16$ slices; $K 0, n=18$ slices. $B, C, I / 0$ curves determined after 2 min (control) and 30 min with $100 \mu \mathrm{m} 4-A P(B)$ or $30 \mu \mathrm{m}$ BDS-I $(\boldsymbol{C})$ in the recording pipette and plotted as described above. The inserts in $\boldsymbol{B}$ depict MF-fEPSP traces from BACE1 WT and KO mice showing responses at $150 \mu \mathrm{A}, 2$ min after pipette insertion (black), and after 30 min (blue). WT, $n=7$ slices; K0, $n=5$ slices (B); WT, $n=5$ slices; K0, $n=7$ slices (C) D, Histograms summarizing the magnitude of drug effect on MF-fEPSP and MF-fiber volley at a stimulating intensity of $150 \mu \mathrm{A}$ for WT and KO. $E$, Insert, Typical MF-fEPSP in response to 5 stimuli at $20 \mathrm{~Hz}$ (50 ms interspike interval) recorded from WT. The diagram shows the normalized MF-fEPSP amplitude relative to that of the first MF-fEPSP. WT, $n=15$ slices; K0, $n=18$ slices. $\boldsymbol{F}$, Train stimuli determined after 5 min (control) and 35 min with $30 \mu \mathrm{m}$ BDS-I in the recording pipette and plotted as in $E$. WT, $n=5$ slices; KO, $n=7$ slices. ${ }^{*} p<0.05$, ${ }^{* *} p<0.01$, ${ }^{* * *} p<0.001$, two-tailed two-sample $t$ test $(\boldsymbol{A}, \boldsymbol{D}, \boldsymbol{E})$, two-tailed paired-sample $t$ test $(\boldsymbol{B}, \boldsymbol{C}, \boldsymbol{F})$.

beads but no antibody and with antibody and beads but no protein rendered no unspecific signals (data not shown). As described previously (Agsten et al., 2015), we used FRAP experiments to assess how the coexpression of a putative interaction partner, here Kv3.4, would alter the diffusion characteristics of BACE1-EGFP in the plasma membrane compared with the coexpression of proteins such as mCherry or epithelial $\mathrm{Na}^{+}$ channel (ENaC-mCherry), which do not associate with BACE1. After a circumscribed region of the membrane was bleached, we monitored the recovery of fluorescence, reflecting BACE1-EGFP diffusion, over time. The time traces were fitted with a monoexponential equation to calculate recovery time constants. Representative traces for the recovery of BACE1-EGFP + Kv3.4 versus BACE1-EGFP + mCherry are shown in Figure $8 C$. When coexpressed with Kv3.4, BACE1-EGFP exhibited a significantly slower recovery time constant $(10.5+0.9 /-0.8 \mathrm{~s})$ than in the presence of mCherry $(7.8+0.4 /-0.4 \mathrm{~s}, p=0.0024)$ or ENaC-
mCherry $(8.0+0.3 /-0.3 \mathrm{~s}, p=0.012)$ (Fig. $8 D$ ), suggesting a physical interaction between BACE1 and Kv3.4.

\section{Overexpression of BACE1 increases Kv3.4 surface levels}

Given that BACE1 deficiency engenders lower surface levels of Kv3.4 protein (Fig. $2 C$ ), we wondered whether the opposite is also true. In other words, would BACE1 overexpression lead to more Kv3.4 channels in the cell membrane? Figure $9 A$ shows a representative Western blot of a surface biotinylation experiment performed in HEK293T cells with and without BACE1 cotransfection. Total and surface proteins were quantified and normalized to the corresponding $\beta$-actin or cadherin signal, respectively. The normalized levels determined in the absence of BACE1 were set to 1 . Consistent with our findings from the mutant hippocampus, in which the lack of BACE1 did not change total Kv3.4 protein, overexpression of BACE1 likewise failed to affect this parameter $(p=$ 0.51; Fig. $9 B$ ). However, BACE1 produced an approximately fourfold increase in the surface level of Kv3.4 ( $p=0.0082$; Fig. 9C). Importantly, a virtually identical enhancement of the Kv3.4 subunit in the cell membrane was achieved when the enzymatic activity of BACE1 was pharmacologically blocked by inhibitor IV ( $p=0.011$; Fig. $9 C$ ). Together with our results from NB-360treated mice (Fig. 5), this finding strongly suggests that pharmacological therapies directed toward the amyloidogenic potency of BACE1 should not interfere with its physiological effect on Kv3.4 channels.

\section{Discussion}

Here, we investigated whether the conspicuous colocalization of BACE1 and Kv3.4, which are both enriched in the MF pathway (Fig. 1), bears significance for the properties of the MF-CA3 synapse. In the hippocampus of BACE1 KO mice, we indeed found a reduced surface level of Kv3.4 protein (Fig. 2). Furthermore, BACE1 deficiency decreased the amount of Kv3.4 protein in synaptic fractions, whereas other presynaptic proteins such as the $\mathrm{Ca}^{2+}$-activated $\mathrm{K}^{+}$channels $\mathrm{K}_{\mathrm{Ca}} 1.1$ and $\mathrm{K}_{\mathrm{Ca}} 2.3$ remained unaffected (Fig. 4), suggesting considerable specificity in how BACE1 tunes the excitability of MFBs.

With fewer Kv3.4 channels in MFBs of BACE1-deficient hippocampi (Fig. 4), we had expected to see at least partially disinhibited postsynaptic responses upon stimulation of MF axons given that Kv3.4 appears to be the major constituent of the current underlying fast repolarization of presynaptic action potentials (see below) (Chang et al., 2007; Alle et al., 2011). However, when we compared MF-fEPSPs between normal and mutant hippocampi, we observed that the postsynaptic responses in the latter were significantly depressed over the entire range of stimulus intensities, leading to a downward shift of the I/O relationship 

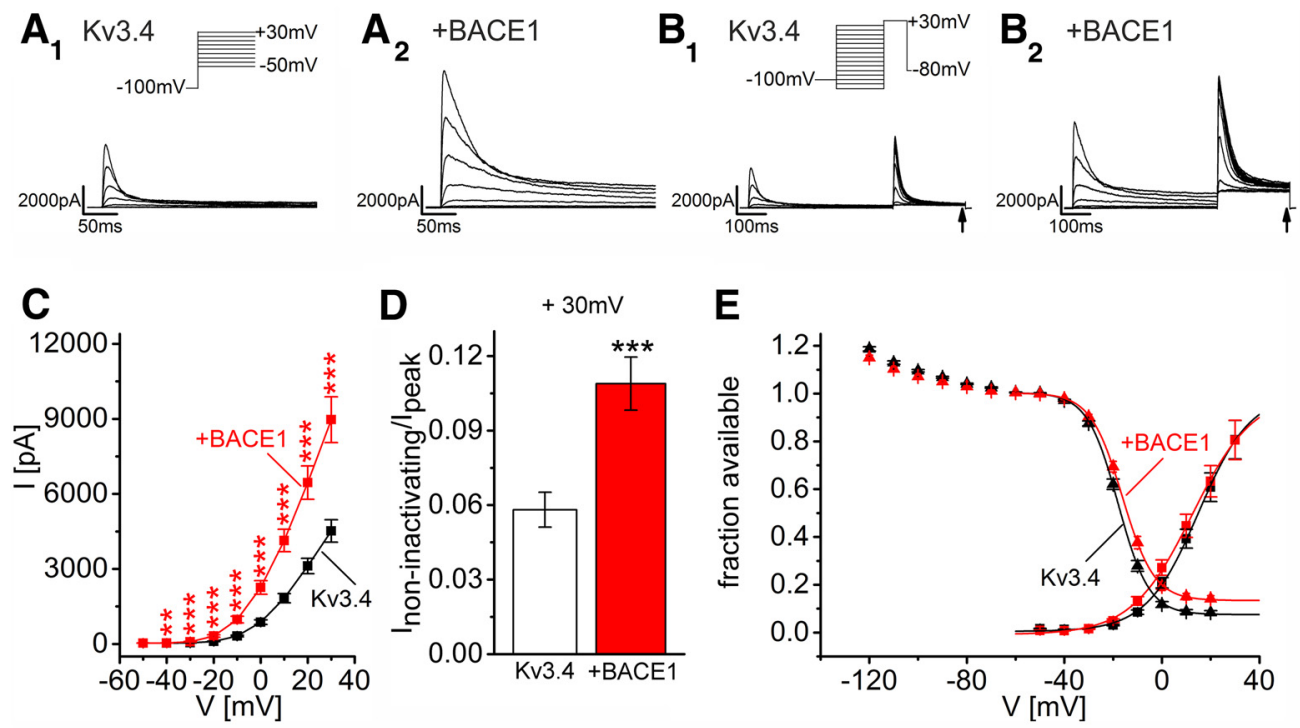

D $\quad+30 \mathrm{mV}$
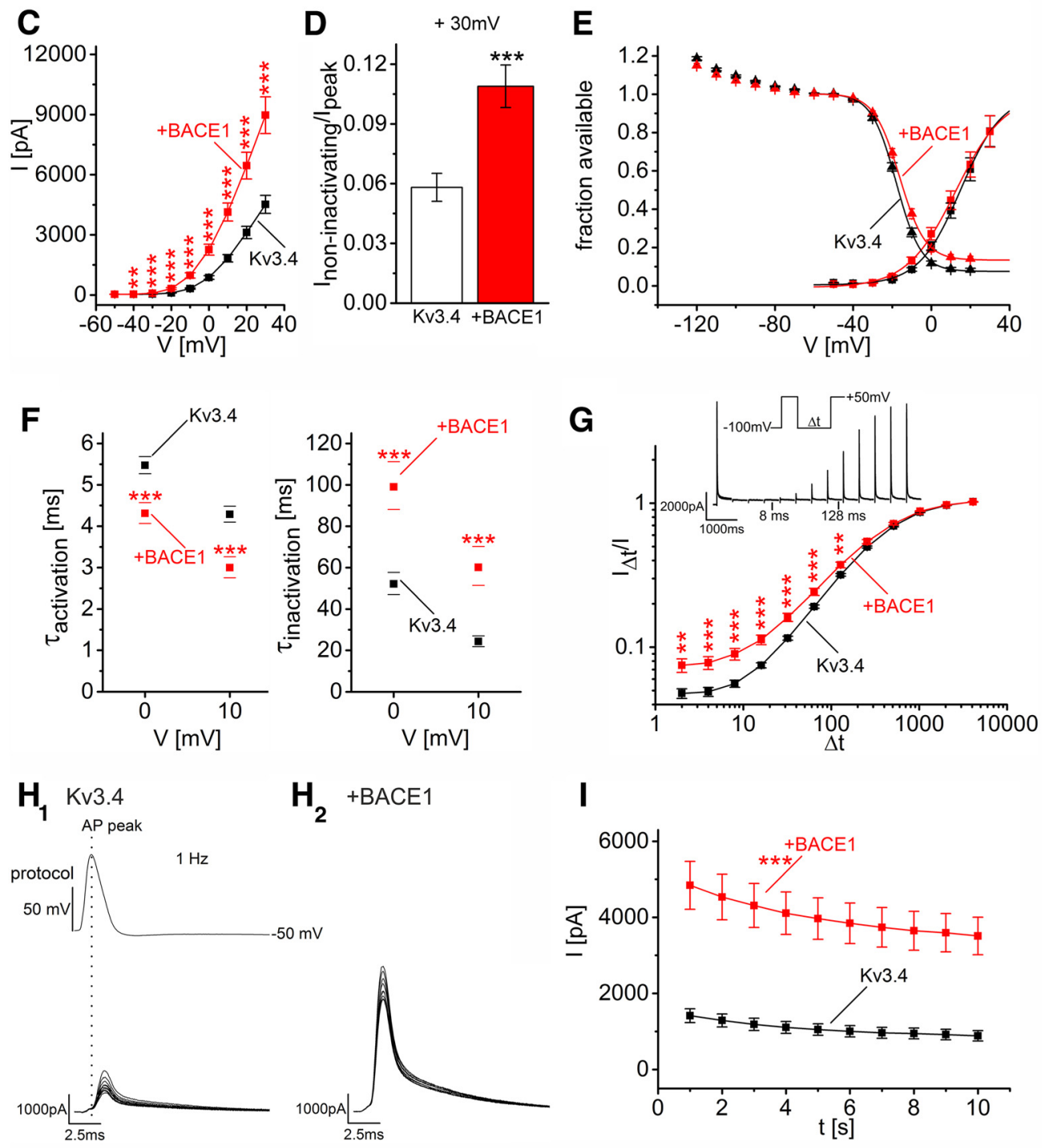

Figure 7. BACE1 amplifies Kv3.4 current and alters channel kinetics in a heterologous expression system. $\boldsymbol{A} 1$ and $\boldsymbol{A 2}$ show representative currents of a cell expressing Kv3.4 (A1) or Kv3.4 with BACE1 ( $\boldsymbol{A 2}$ ) recorded with the activation protocol shown in the inset. $\boldsymbol{B} 1$ and $\boldsymbol{B 2}$ display representative currents of a Kv3.4-expressing (B1) or Kv3.4 + BACE1-expressing (B2) cell recorded with the inactivation protocol shown in the inset. C, The I-V relationship was generated from Kv3.4 peak currents plotted as function of test potentials from $-50 \mathrm{mV}$ to $+30 \mathrm{mV}$, Kv3.4, $n=60 ;+B A C E 1$, $n=44$. $\boldsymbol{D}$, Relative noninactivating current was calculated as steady-state current divided by peak current. Peak current was determined from the test pulse at $+30 \mathrm{mV}$ after a prepulse at -120 $\mathrm{mV}(\boldsymbol{B} 1, \boldsymbol{B} 2$, prepulse duration $500 \mathrm{~ms})$. Steady-state current was obtained from recordings with a prepulse at $+20 \mathrm{mV}$ that activated and inactivated approximately all channels, resulting in no peak and only noninactivating steady-state current at $+30 \mathrm{mV}$. This steady-state current was averaged over the last $28 \mathrm{~ms}$ of the test pulse (see arrow in $B 1$ and $B 2$ ). Kv3.4, $n=49 ;+B A C E 1, n=36$. $\boldsymbol{E}$, Voltage-dependent activation (squares) and inactivation (triangles) curves. Activation: conductance was generated from mean peak current $(\boldsymbol{C})$. The graphs present the mean conductance fitted with a Boltzmann equation and normalized to the upper asymptote. Kv3.4, $n=60 ;+B A C E 1, n=44$. Inactivation: current amplitudes of individual recordings from test pulses after prepulses of $-60 \mathrm{mV}$ to $+20 \mathrm{mV}$ recorded with the inactivation protocol (B1) were fitted with a Boltzmann equation. Peak current values were normalized to the upper asymptote. Kv3.4, $n=49 ;+B A C E 1$,

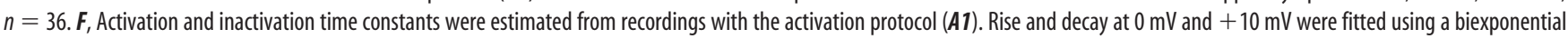
function to determine activation and inactivation kinetics, respectively. $0 \mathrm{mV}: \mathrm{Kv} 3.4, n=50 ;+\mathrm{BACE} 1, n=38 ;+10 \mathrm{mV}: \mathrm{Kv} 3.4, n=50 ;+$ BACE1, $n=39$. Statistical significance of time constants was tested on logarithmically transformed data. For illustration, time constant means \pm SEM were back-transformed to a linear scale. $\mathbf{G}$, Time-dependent recovery from channel inactivation recorded with the protocol shown in the inset with varying interpulse intervals $\Delta t=2^{i}[\mathrm{~ms}], i=1-12$. Graph shows time-dependent recovery of peak current after inactivation $\left(I_{\Delta \mathrm{t})}\right.$ normalized to the peak before channel inactivation (I). Kv3.4, $n=44 ;+B A C E 1, n=23$. $\boldsymbol{H}$, Representative currents of a cell expressing Kv3.4 or Kv3.4 + BACE1 in response to 10 command protocols of the AP waveform with $1 \mathrm{~Hz}$. I, Graphs generated from Kv3.4 peak currents recorded with the command protocol shown in $\boldsymbol{H}$. Kv3.4, $n=50$; + BACE1, $n=42$. D, E Inactivation, $\boldsymbol{F}, \boldsymbol{G}, \boldsymbol{I}$, Cells with peak currents $<2 \mathrm{nA}$ at $+80 \mathrm{mV}$ in the activation protocol (A1) were excluded from analysis. Statistics: ${ }^{* *} p<0.01$, ${ }^{* * *} p<0.001$, normally distributed data were tested using a two-tailed two-sample $t$ test $(\boldsymbol{F})$; datasets showing no normal distribution were tested using a two-tailed Mann-Whitney test $(\boldsymbol{C}, \mathbf{D}, \mathbf{G}, \boldsymbol{I})$. 
A
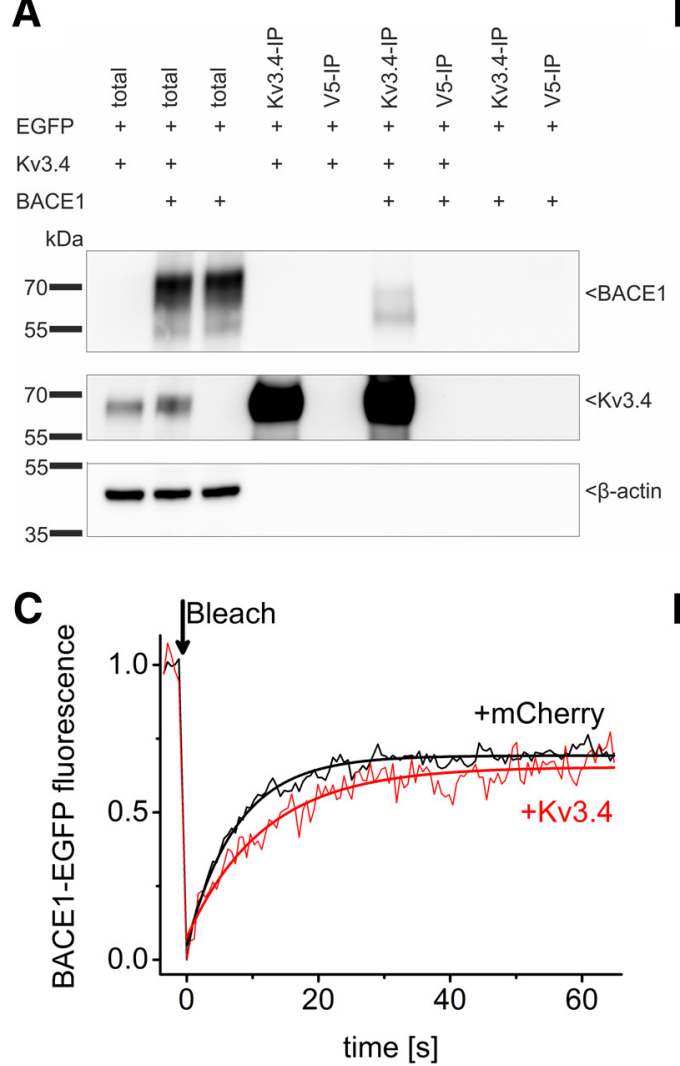

B

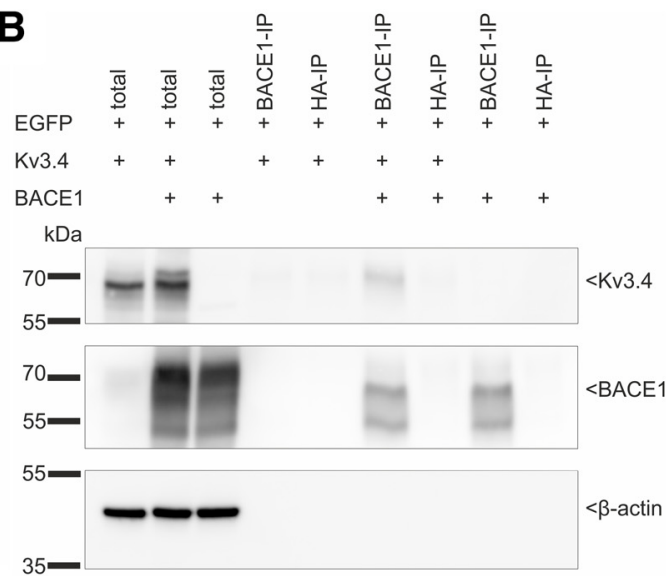

D

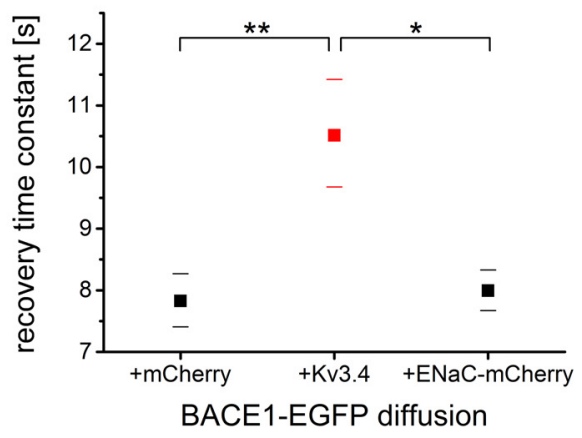

Figure 8. BACE1 interacts directly with Kv3.4. $\boldsymbol{A}, \boldsymbol{B}$, Representative Western blot of a Kv3.4-IP with BACE1 co-IP $(\boldsymbol{A}, n=3)$ or BACE1-IP with Kv3.4 co-IP $(\boldsymbol{B}, n=2)$ and the corresponding isotype controls in transfected HEK293T cells. EGFP served as transfection marker. C, FRAP experiments. Example traces of BACE1-EGFP fluorescence upon coexpression of $m$ Cherry (black) or Kv3.4 (red) with corresponding fit curves using the equation $I(t)=A^{*} e^{-t / \tau}+I_{0}$ are shown. $\boldsymbol{D}$, Recovery time constants of BACE1-EGFP coexpressed with the constructs as indicated below the graph. Statistical significance of time constants was tested on logarithmically transformed data. ${ }^{*} p<0.05,{ }^{* *} p<0.01$, one-way ANOVA with post hoc Tukey test. For illustration, time constant means \pm SEM were back-transformed to a linear scale. + mCherry, $n=46 ;+\mathrm{Kv} 3.4, n=29 ;+$ ENaC-mCherry, $n=31$.

(Fig. 6A). Obviously, genetic disruption of Bace1 must have altered synaptic properties in addition to Kv3.4 activity in MF terminals. However, when we used BDS-I, we obtained evidence that the contribution of Kv3.4 to the control of presynaptic transmitter release was significantly diminished in BACE1 ${ }^{-/-}$hippocampi (Fig. 6C,D).

In this context, it is worth noting that BDS-I was introduced as a selective, high-affinity blocker of homomeric Kv3.4 channels in oocyte and mammalian expression systems (Diochot et al., 1998), but was later found to also inhibit Kv3.1- and Kv3.2-mediated currents and, perhaps, Kv3.3-mediated currents (Yeung et al., 2005; Martina et al., 2007). On pharmacological grounds alone, we can therefore not unequivocally attribute the BDS-I-mediated enhancement of MF-fEPSPs to a selective suppression of Kv3.4 channels. However, in immunohistological experiments on mouse hippocampus, expression of both Kv3.3 and Kv3.4 is robust in MFs, whereas no appreciable staining for Kv3.1b and Kv.3.2 was detected in this pathway (Chang et al., 2007). Regarding the contribution of Kv channels other than Kv3, 4-AP, which blocks Kv3 and Kv1, did not produce a significantly stronger enhancement of MF-fEPSPs than BDS-I (Fig. 6B,D). Finally, Alle et al. (2011) reported that, in MFBs, action potential waveforms recruit Kv3 channels four times better than Kv1 channels. From the combined pharmacological, immunohistological, and electrophysiological evidence presented here and in previous work, it seems reasonable to conclude that the Kv3 current of MFBs is predominantly generated by Kv3.4-subunit-containing channels.
In principle, the depression of synaptic responses at the MFCA3 synapse in BACE1-null hippocampus, which was strong enough to conceal the concomitant decline in Kv3.4-mediated current, might be presynaptic or postsynaptic in nature or result from a combination of both. Pronounced facilitation during repetitive stimulation is a distinguishing feature of this synapse (Nicoll and Schmitz, 2005) and, when we probed this form of short-term plasticity, facilitation proved stronger in the mutant than in the WT hippocampus, arguing against a postsynaptic mechanism (Fig. 6E). MFBs are known to exhibit low release probability upon single stimulation (Nicoll and Schmitz, 2005). Therefore, in the absence of BACE1, glutamate release seems to be further reduced, explaining the depressed I/O curve, which would, in turn, widen the range of short-term plasticity, explaining enhanced facilitation. Lending support to a presynaptic site of BACE1 action, a severe presynaptic phenotype of the MF-CA3 synapse in BACE1 KO mice has been reported previously, including increased paired-pulse ratio and loss of long-term potentiation (Wang et al., 2008). Although the underlying mechanism awaits further study, the evidence gathered so far links the electrophysiological phenotype to abnormal presynaptic $\mathrm{Ca}^{2+}$ handling (Wang et al., 2008, 2010). We found that Kv3.4 and its regulation by BACE1 were not involved in short-term plasticity (Fig. $6 F$ ), consistent with the notion that the channel mainly serves to promote temporal fidelity of signal transfer at this synapse by keeping presynaptic action potentials short. 
A

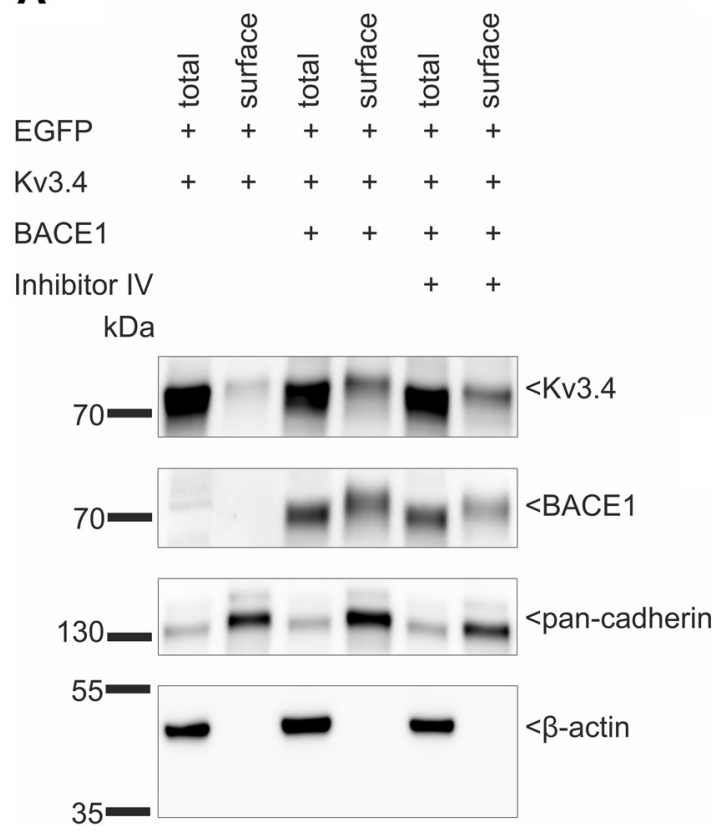

B

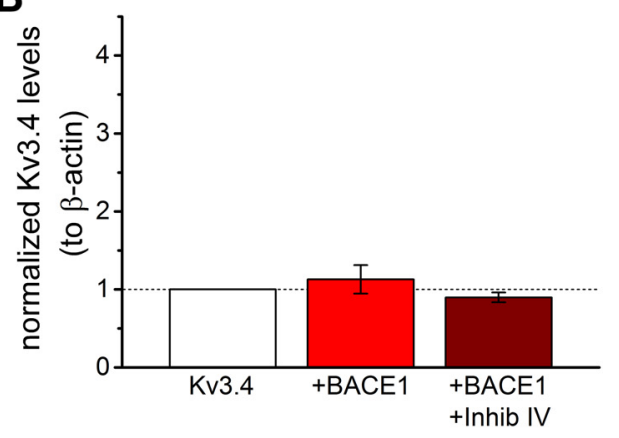

C

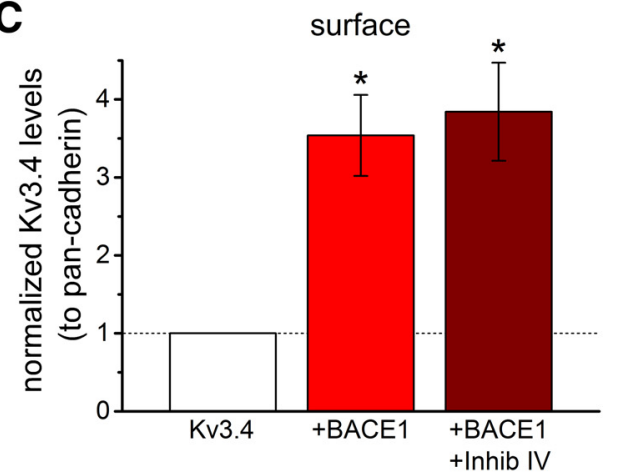

Figure 9. BACE1 increases Kv3.4 surface level independent of its proteolytic activity in HEK293T cells. $A$, Representative Western blot of a surface biotinylation experiment of HEK293T cells. Transfected constructs and treatment with $5 \mu \mathrm{m}$ BACE1 inhibitor IV are depicted above the blot. EGFP served as transfection marker. B, Total levels of Kv3.4 normalized to the corresponding total levels of $\beta$-actin, with the normalized levels determined in the absence of BACE1 set to 1. C, Surface levels of Kv3.4 normalized to the corresponding surface levels of pan-cadherin, with the normalized levels determined in the absence of BACE1 set to $1 . n=5,{ }^{*} p<0.05$, two-tailed one-sample $t$ test with Bonferroni correction.

In view of the reduced efficiency of basal transmission at the MF-CA3 synapse in BACE1 ${ }^{-1-}$ hippocampus, the apparent downregulation of Kv3.4 current in MFBs might represent a compensatory mechanism to counteract excessive lowering of transmitter release rather than being causally linked to the absence of BACE1 per se. In the native preparation, we cannot differentiate conclusively between these two alternatives, but our experiments with heterologously expressed Kv3.4 clearly demonstrated that cotransfection of BACE1 did have a considerable impact on the surface levels (Fig. 9) and biophysical properties of the channel (Fig. 7) and that BACE1 and Kv3.4 are directly associated with each other (Fig. 8).

The enhancement of a voltage-dependent cation current through close interaction of BACE1 with the channel protein is not without precedent. We have reported previously that BACE1 can assume the role of an auxiliary channel subunit ( $\beta$-subunit) that binds to the main $(\alpha-)$ subunit of voltage-gated $\mathrm{Na}^{+}$(Huth et al., 2009) and KCNQ (Kv7) channels (Agsten et al., 2015; Hessler et al., 2015). Through the direct, nonenzymatic interaction with the channel protein, BACE1 gains considerable control over decisive channel properties, thereby affecting the excitability of neurons in the brain or possibly myocytes in the heart. With respect to KCNQ, BACE1 strongly modified their gating properties to boost channel activity, but did not appear to alter channel density in the cell membrane (Hessler et al., 2015). Here, the effect of BACE1 was the opposite. Whereas only moderately influencing channel kinetics (Fig. 7), BACE1 amplified Kv3.4 current by increasing the number of channels in the membrane (Fig. 9). Again, this effect was independent of the enzymatic activity of BACE1, suggesting that BACE1-Kv3.4 complexes might reach the cell membrane more easily than the channel alone. The notion of a direct interaction was also supported by the treatment of C57BL/6 mice with the BACE inhibitor NB-360, which did not affect synaptic Kv3.4 levels significantly (Fig. 5).

Our first data on Kv3.4 trafficking also showed that BACE1 should have an impact on axonal transport of Kv3.4 while being present in the same vesicular structures (Fig. 3). This finding fits nicely with the notion that the intracellular trafficking route of BACE1 is well suited for its interaction with various partners (Buggia-Prévot and Thinakaran, 2015). Therefore, BACE1 seems to be especially required to promote Kv3.4 trafficking and surface targeting, unveiling a new aspect in the regulation of voltagedependent $\mathrm{K}^{+}$channels by BACE1.

Gene expression profiling of samples of human cerebral cortex at different stages of AD revealed an early upregulation of Kv3.4 mRNA, which persisted into late stages of the disease (Angulo et al., 2004). Upregulation of Kv3.4 protein in early AD brains occurred before the appearance of amyloid plaques and neurofibrillary tangles, which led Angulo et al. (2004) to speculate that soluble $\mathrm{A} \beta$ peptide might be responsible for the early increase in Kv3.4. In cultured neurons, $A \beta$ peptide indeed produced an increase in Kv3.4 expression and current that was linked to neuronal apoptosis (Pannaccione et al., 2007). Ample evidence indicates that cellular stress factors such as mitochondrial dysfunction, oxidative stress, and $\mathrm{Ca}^{2+}$ dysregulation elevate BACE1 levels, giving rise to a vicious cycle in which comorbidity factors drive $\mathrm{BACE} 1$, thereby enhancing the formation of toxic $\mathrm{A} \beta$ peptides and thus accelerating the progression of cognitive impairment and dementia in AD (Chami and Checler, 2012). In fact, BACE1 expression is increased in patients with mild cognitive impairment and in AD (Yang et al., 2003; Tesco et al., 2007; Cheng et al., 2014). Although our data suggest that pathologically increased levels of BACE1 are unlikely to augment formation of new Kv3.4 proteins (Figs. 2B, 4, 9B), BACE1 might be instrumen- 
tal to facilitate their surface trafficking, thereby rendering the channels functional.

Does the upregulation of Kv3.4 promote the progression of AD, as Angulo et al. (2004) and Pannaccione et al. (2007) proposed, advancing the channel as a new therapeutic target, or can the increase in Kv3.4 be understood as an effort to compensate for the increasing network instability in $\mathrm{AD}$ (Huang and Mucke, 2012; Sheng et al., 2012; Keskin et al., 2017)? Regarding the MF pathway, histological and electrophysiological studies in mouse models of AD showed that high levels of BACE1 localize to dystrophic presynaptic terminals in CA3 stratum lucidum (Sadleir et al., 2016) and that the MF-CA3 synapse is the first to become dysfunctional (Lee et al., 2012; Wilke et al., 2014). It remains to be determined whether, under such rapidly deteriorating conditions, Kv3.4 protein will reach the terminal and, if so, whether it will improve or impair the residual functionality of the synapse.

\section{References}

Agsten M, Hessler S, Lehnert S, Volk T, Rittger A, Hartmann S, Raab C, Kim DY, Groemer TW, Schwake M, Alzheimer C, Huth T (2015) BACE1 modulates gating of KCNQ1 (Kv7.1) and cardiac delayed rectifier KCNQ1/KCNE1 (IKs). J Mol Cell Cardiol 89:335-348. CrossRef Medline

Alle H, Kubota H, Geiger JR (2011) Sparse but highly efficient Kv3 outpace BKCa channels in action potential repolarization at hippocampal mossy fiber boutons. J Neurosci 31:8001-8012. CrossRef Medline

Angulo E, Noé V, Casadó V, Mallol J, Gomez-Isla T, Lluis C, Ferrer I, Ciudad CJ, Franco R (2004) Up-regulation of the Kv3.4 potassium channel subunit in early stages of Alzheimer's disease. J Neurochem 91:547-557. CrossRef Medline

Bhattacharyya R, Barren C, Kovacs DM (2013) Palmitoylation of amyloid precursor protein regulates amyloidogenic processing in lipid rafts. J Neurosci 33:11169-11183. CrossRef Medline

Bischofberger J, Engel D, Frotscher M, Jonas P (2006) Timing and efficacy of transmitter release at mossy fiber synapses in the hippocampal network. Pflugers Arch 453:361-372. CrossRef Medline

Buggia-Prévot V, Thinakaran G (2015) Significance of transcytosis in Alzheimer's disease: BACE1 takes the scenic route to axons. Bioessays 37: 888-898. CrossRef Medline

Buggia-Prévot V, Fernandez CG, Riordan S, Vetrivel KS, Roseman J, Waters J, Bindokas VP, Vassar R, Thinakaran G (2014) Axonal BACE1 dynamics and targeting in hippocampal neurons: a role for Rab11 GTPase. Mol Neurodegener 9:1. CrossRef Medline

Cai H, Wang Y, McCarthy D, Wen H, Borchelt DR, Price DL, Wong PC (2001) BACE1 is the major beta-secretase for generation of abeta peptides by neurons. Nat Neurosci 4:233-234. CrossRef Medline

Cao L, Rickenbacher GT, Rodriguez S, Moulia TW, Albers MW (2012) The precision of axon targeting of mouse olfactory sensory neurons requires the BACE1 protease. Sci Rep 2:231. CrossRef Medline

Chami L, Checler F (2012) BACE1 is at the crossroad of a toxic vicious cycle involving cellular stress and beta-amyloid production in Alzheimer's disease. Mol Neurodegener 7:52. CrossRef Medline

Chang SY, Zagha E, Kwon ES, Ozaita A, Bobik M, Martone ME, Ellisman MH, Heintz N, Rudy B (2007) Distribution of Kv3.3 potassium channel subunits in distinct neuronal populations of mouse brain. J Comp Neurol 502:953-972. CrossRef Medline

Cheng X, He P, Lee T, Yao H, Li R, Shen Y (2014) High activities of BACE1 in brains with mild cognitive impairment. Am J Pathol 184:141-147. CrossRef Medline

Das U, Wang L, Ganguly A, Saikia JM, Wagner SL, Koo EH, Roy S (2016) Visualizing APP and BACE-1 approximation in neurons yields insight into the amyloidogenic pathway. Nat Neurosci 19:55-64. CrossRef Medline

Diochot S, Schweitz H, Béress L, Lazdunski M (1998) Sea anemone peptides with a specific blocking activity against the fast inactivating potassium channel Kv3.4. J Biol Chem 273:6744-6749. CrossRef Medline

Dominguez D, Tournoy J, Hartmann D, Huth T, Cryns K, Deforce S, Serneels L, Camacho IE, Marjaux E, Craessaerts K, Roebroek AJ, Schwake M, D’Hooge R, Bach P, Kalinke U, Moechars D, Alzheimer C, Reiss K, Saftig P, De Strooper B (2005) Phenotypic and biochemical analyses of BACE1- and BACE2-deficient mice. J Biol Chem 280:30797-30806. CrossRef Medline
Fineberg JD, Ritter DM, Covarrubias M (2012) Modeling-independent elucidation of inactivation pathways in recombinant and native A-type kv channels. J Gen Physiol 140:513-527. CrossRef Medline

Gautam V, D’Avanzo C, Hebisch M, Kovacs DM, Kim DY (2014) BACE1 activity regulates cell surface contactin-2 levels. Mol Neurodegener 9:4. CrossRef Medline

Goldberg EM, Watanabe S, Chang SY, Joho RH, Huang ZJ, Leonard CS, Rudy B (2005) Specific functions of synaptically localized potassium channels in synaptic transmission at the neocortical GABAergic fast-spiking cell synapse. J Neurosci 25:5230-5235. CrossRef Medline

Gu Y, Gu C (2010) Dynamics of Kv1 channel transport in axons. PLoS One 5:e11931. CrossRef Medline

Hessler S, Zheng F, Hartmann S, Rittger A, Lehnert S, Völkel M, Nissen M, Edelmann E, Saftig P, Schwake M, Huth T, Alzheimer C (2015) betasecretase BACE1 regulates hippocampal and reconstituted M-currents in a beta-subunit-like fashion. J Neurosci 35:3298-3311. CrossRef Medline

Hirokawa N, Niwa S, Tanaka Y (2010) Molecular motors in neurons: transport mechanisms and roles in brain function, development, and disease. Neuron 68:610-638. CrossRef Medline

Hitt BD, Jaramillo TC, Chetkovich DM, Vassar R (2010) BACE1-/- mice exhibit seizure activity that does not correlate with sodium channel level or axonal localization. Mol Neurodegener 5:31. CrossRef Medline

Huang Y, Mucke L (2012) Alzheimer mechanisms and therapeutic strategies. Cell 148:1204-1222. CrossRef Medline

Hu X, Zhou X, He W, Yang J, Xiong W, Wong P, Wilson CG, Yan R (2010) BACE1 deficiency causes altered neuronal activity and neurodegeneration. J Neurosci 30:8819-8829. CrossRef Medline

Huth T, Schmidt-Neuenfeldt K, Rittger A, Saftig P, Reiss K, Alzheimer C (2009) Non-proteolytic effect of beta-site APP-cleaving enzyme 1 (BACE1) on sodium channel function. Neurobiol Dis 33:282-289. CrossRef Medline

Ishikawa T, Nakamura Y, Saitoh N, Li WB, Iwasaki S, Takahashi T (2003) Distinct roles of $\mathrm{Kv} 1$ and $\mathrm{Kv} 3$ potassium channels at the calyx of held presynaptic terminal. J Neurosci 23:10445-10453. Medline

Kaczmarek LK, Zhang Y (2017) Kv3 channels: enablers of rapid firing, neurotransmitter release, and neuronal endurance. Physiol Rev 97:14311468. CrossRef Medline

Kandalepas PC, Sadleir KR, Eimer WA, Zhao J, Nicholson DA, Vassar R (2013) The Alzheimer's beta-secretase BACE1 localizes to normal presynaptic terminals and to dystrophic presynaptic terminals surrounding amyloid plaques. Acta Neuropathol 126:329-352. CrossRef Medline

Kerr AM, Jonas P (2008) The two sides of hippocampal mossy fiber plasticity. Neuron 57:5-7. CrossRef Medline

Keskin AD, Kekuš M, Adelsberger H, Neumann U, Shimshek DR, Song B, Zott B, Peng T, Förstl H, Staufenbiel M, Nelken I, Sakmann B, Konnerth A, Busche MA (2017) BACE inhibition-dependent repair of Alzheimer's pathophysiology. Proc Natl Acad Sci U S A 114:8631-8636. CrossRef Medline

Kim DY, Kovacs DM (2011) Surface trafficking of sodium channels in cells and in hippocampal slices. Methods Mol Biol 793:351-361. CrossRef Medline

Kim DY, Carey BW, Wang H, Ingano LA, Binshtok AM, Wertz MH, Pettingell WH, He P, Lee VM, Woolf CJ, Kovacs DM (2007) BACE1 regulates voltage-gated sodium channels and neuronal activity. Nat Cell Biol 9:755-764. CrossRef Medline

Kim DY, Gersbacher MT, Inquimbert P, Kovacs DM (2011) Reduced sodium channel $\mathrm{Na}(\mathrm{v}) 1.1$ levels in BACE1-null mice. J Biol Chem 286: 8106-8116. CrossRef Medline

Kuhn PH, Koroniak K, Hogl S, Colombo A, Zeitschel U, Willem M, Volbracht C, Schepers U, Imhof A, Hoffmeister A, Haass C, Roßner S, Bräse S, Lichtenthaler SF (2012) Secretome protein enrichment identifies physiological BACE1 protease substrates in neurons. EMBO J 31:31573168. CrossRef Medline

Laird FM, Cai H, Savonenko AV, Farah MH, He K, Melnikova T, Wen H, Chiang HC, Xu G, Koliatsos VE, Borchelt DR, Price DL, Lee HK, Wong PC (2005) BACE1, a major determinant of selective vulnerability of the brain to amyloid-beta amyloidogenesis, is essential for cognitive, emotional, and synaptic functions. J Neurosci 25:11693-11709. CrossRef Medline

Lee SH, Kim KR, Ryu SY, Son S, Hong HS, Mook-Jung I, Lee SH, Ho WK (2012) Impaired short-term plasticity in mossy fiber synapses caused by mitochondrial dysfunction of dentate granule cells is the earliest synaptic deficit in a mouse model of Alzheimer's disease. J Neurosci 32:5953-5963. CrossRef Medline 
Lehnert S, Hartmann S, Hessler S, Adelsberger H, Huth T, Alzheimer C (2016) Ion channel regulation by beta-secretase BACE1: enzymatic and non-enzymatic effects beyond Alzheimer's disease. Channels (Austin) 10: 365-378. CrossRef Medline

Linkert M, Rueden CT, Allan C, Burel JM, Moore W, Patterson A, Loranger B, Moore J, Neves C, Macdonald D, Tarkowska A, Sticco C, Hill E, Rossner M, Eliceiri KW, Swedlow JR (2010) Metadata matters: access to image data in the real world. J Cell Biol 189:777-782. CrossRef Medline

Martina M, Metz AE, Bean BP (2007) Voltage-dependent potassium currents during fast spikes of rat cerebellar Purkinje neurons: inhibition by BDS-I toxin. J Neurophysiol 97:563-571. CrossRef Medline

Meijering E, Jacob M, Sarria JC, Steiner P, Hirling H, Unser M (2004) Design and validation of a tool for neurite tracing and analysis in fluorescence microscopy images. Cytometry A 58:167-176. CrossRef Medline

Munro KM, Nash A, Pigoni M, Lichtenthaler SF, Gunnersen JM (2016) Functions of the Alzheimer's disease protease BACE1 at the synapse in the central nervous system. J Mol Neurosci 60:305-315. CrossRef Medline

Neumann U, Rueeger H, Machauer R, Veenstra SJ, Lueoend RM, TintelnotBlomley M, Laue G, Beltz K, Vogg B, Schmid P, Frieauff W, Shimshek DR, Staufenbiel M, Jacobson LH (2015) A novel BACE inhibitor NB-360 shows a superior pharmacological profile and robust reduction of amyloid-beta and neuroinflammation in APP transgenic mice. Mol Neurodegener 10:44. CrossRef Medline

Nicoll RA, Schmitz D (2005) Synaptic plasticity at hippocampal mossy fibre synapses. Nat Rev Neurosci 6:863-876. CrossRef Medline

Pannaccione A, Boscia F, Scorziello A, Adornetto A, Castaldo P, Sirabella R, Taglialatela M, Di Renzo GF, Annunziato L (2007) Up-regulation and increased activity of KV3.4 channels and their accessory subunit MinKrelated peptide 2 induced by amyloid peptide are involved in apoptotic neuronal death. Mol Pharmacol 72:665-673. CrossRef Medline

Peters F, Salihoglu H, Rodrigues E, Herzog E, Blume T, Filser S, Dorostkar M, Shimshek DR, Brose N, Neumann U, Herms J (2018) BACE1 inhibition more effectively suppresses initiation than progression of beta-amyloid pathology. Acta Neuropathol. Advance online publication. Retrieved January 11, 2018. CrossRef

Prüss H, Grosse G, Brunk I, Veh RW, Ahnert-Hilger G (2010) Agedependent axonal expression of potassium channel proteins during development in mouse hippocampus. Histochem Cell Biol 133:301-312. CrossRef Medline

Riazanski V, Becker A, Chen J, Sochivko D, Lie A, Wiestler OD, Elger CE, Beck H (2001) Functional and molecular analysis of transient voltage-dependent $\mathrm{K}+$ currents in rat hippocampal granule cells. J Physiol 537:391-406. CrossRef Medline

Ritter DM, Zemel BM, Hala TJ, O’Leary ME, Lepore AC, Covarrubias M (2015) Dysregulation of Kv3.4 channels in dorsal root ganglia following spinal cord injury. J Neurosci 35:1260-1273. CrossRef Medline

Rowan MJ, DelCanto G, Yu JJ, Kamasawa N, Christie JM (2016) Synapselevel determination of action potential duration by $\mathrm{K}(+)$ channel clustering in axons. Neuron 91:370-383. CrossRef Medline

Rudy B, McBain CJ (2001) Kv3 channels: voltage-gated K+ channels designed for high-frequency repetitive firing. Trends Neurosci 24:517-526. CrossRef Medline

Sachse CC, Kim YH, Agsten M, Huth T, Alzheimer C, Kovacs DM, Kim DY (2013) BACE1 and presenilin/gamma-secretase regulate proteolytic processing of KCNE1 and 2, auxiliary subunits of voltage-gated potassium channels. FASEB J 27:2458-2467. CrossRef Medline

Sadleir KR, Kandalepas PC, Buggia-Prévot V, Nicholson DA, Thinakaran G, Vassar R (2016) Presynaptic dystrophic neurites surrounding amyloid plaques are sites of microtubule disruption, BACE1 elevation, and increased Abeta generation in Alzheimer's disease. Acta Neuropathol 132: 235-256. CrossRef Medline

Schindelin J, Arganda-Carreras I, Frise E, Kaynig V, Longair M, Pietzsch T, Preibisch S, Rueden C, Saalfeld S, Schmid B, Tinevez JY, White DJ,
Hartenstein V, Eliceiri K, Tomancak P, Cardona A (2012) Fiji: an opensource platform for biological-image analysis. Nat Methods 9:676-682. CrossRef Medline

Sheng M, Sabatini BL, Sudhof TC (2012) Synapses and Alzheimer's disease. Cold Spring Harb Perspect Biol 4: pii: a005777. CrossRef Medline

Shimshek DR, Jacobson LH, Kolly C, Zamurovic N, Balavenkatraman KK, Morawiec L, Kreutzer R, Schelle J, Jucker M, Bertschi B, Theil D, Heier A, Bigot K, Beltz K, Machauer R, Brzak I, Perrot L, Neumann U (2016) Pharmacological BACE1 and BACE2 inhibition induces hair depigmentation by inhibiting PMEL17 processing in mice. Sci Rep 6:21917. CrossRef Medline

Tesco G, Koh YH, Kang EL, Cameron AN, Das S, Sena-Esteves M, Hiltunen M, Yang SH, Zhong Z, Shen Y, Simpkins JW, Tanzi RE (2007) Depletion of GGA3 stabilizes BACE and enhances beta-secretase activity. Neuron 54:721-737. CrossRef Medline

Trimmer JS (2015) Subcellular localization of K+ channels in mammalian brain neurons: remarkable precision in the midst of extraordinary complexity. Neuron 85:238-256. CrossRef Medline

Vassar R, Kuhn PH, Haass C, Kennedy ME, Rajendran L, Wong PC, Lichtenthaler SF (2014) Function, therapeutic potential and cell biology of BACE proteases: current status and future prospects. J Neurochem 130: 4-28. CrossRef Medline

Wang H, Song L, Laird F, Wong PC, Lee HK (2008) BACE1 knock-outs display deficits in activity-dependent potentiation of synaptic transmission at mossy fiber to CA3 synapses in the hippocampus. J Neurosci 28:8677-8681. CrossRef Medline

Wang H, Song L, Lee A, Laird F, Wong PC, Lee HK (2010) Mossy fiber long-term potentiation deficits in BACE1 knock-outs can be rescued by activation of alpha7 nicotinic acetylcholine receptors. J Neurosci 30: 13808-13813. CrossRef Medline

Welzel O, Tischbirek CH, Jung J, Kohler EM, Svetlitchny A, Henkel AW, Kornhuber J, Groemer TW (2010) Synapse clusters are preferentially formed by synapses with large recycling pool sizes. PLoS One 5:e13514. CrossRef Medline

Wilke SA, Raam T, Antonios JK, Bushong EA, Koo EH, Ellisman MH, Ghosh A (2014) Specific disruption of hippocampal mossy fiber synapses in a mouse model of familial Alzheimer's disease. PLoS One 9:e84349. CrossRef Medline

Willem M, Garratt AN, Novak B, Citron M, Kaufmann S, Rittger A, DeStrooper B, Saftig P, Birchmeier C, Haass C (2006) Control of peripheral nerve myelination by the beta-secretase BACE1. Science 314: 664-666. CrossRef Medline

Yan R (2017) Physiological functions of the beta-site amyloid precursor protein cleaving enzyme 1 and 2. Front Mol Neurosci 10:97. CrossRef Medline

Yang LB, Lindholm K, Yan R, Citron M, Xia W, Yang XL, Beach T, Sue L, Wong P, Price D, Li R, Shen Y (2003) Elevated beta-secretase expression and enzymatic activity detected in sporadic Alzheimer disease. Nat Med 9:3-4. CrossRef Medline

Ye X, Feng T, Tammineni P, Chang Q, Jeong YY, Margolis DJ, Cai H, Kusnecov A, Cai Q (2017) Regulation of synaptic amyloid-beta generation through BACE1 retrograde transport in a mouse model of Alzheimer's disease. J Neurosci 37:2639-2655. CrossRef Medline

Yeung SY, Thompson D, Wang Z, Fedida D, Robertson B (2005) Modulation of Kv3 subfamily potassium currents by the sea anemone toxin BDS: significance for CNS and biophysical studies. J Neurosci 25:8735-8745. CrossRef Medline

Zhao J, Fu Y, Yasvoina M, Shao P, Hitt B, O’Connor T, Logan S, Maus E, Citron M, Berry R, Binder L, Vassar R (2007) Beta-site amyloid precursor protein cleaving enzyme 1 levels become elevated in neurons around amyloid plaques: implications for Alzheimer's disease pathogenesis. J Neurosci 27:3639-3649. CrossRef Medline 